\title{
Molecular phylogeny of the Notostraca
}

\author{
Michael Korn ${ }^{\mathrm{a}, \mathrm{b}, *}$, Nicolas Rabet ${ }^{\mathrm{c}}$, Hemant V. Ghate ${ }^{\mathrm{d}}$, Federico Marrone ${ }^{\mathrm{e}}$, Anna K. Hundsdoerfer ${ }^{\mathrm{a}}$ \\ ${ }^{a}$ DNA-Laboratory, Museum of Zoology, Senckenberg Natural History Collections Dresden, Königsbrücker Landstrasse 159, D-01109 Dresden, Germany \\ ${ }^{\mathrm{b}}$ Limnological Institute, University of Konstanz, Mainaustr. 252, D-78464 Konstanz, Germany \\ ${ }^{\mathrm{C}}$ MNHN, UPMC, CNRS, IRD, UMR, 7208 BOREA 43, rue Cuvier, 75005 Paris, France \\ ${ }^{\mathrm{d}}$ Department of Zoology, Modern College, Shivajinagar, Pune 411 005, India \\ e Dipartimento di Scienze e Tecnologie Biologiche, Chimiche e Farmaceutiche, Università di Palermo, via Archirafi 18, I-90123 Palermo, Italy
}

\section{A R T I C L E I N F O}

\section{Article history:}

Received 3 November 2012

Revised 11 July 2013

Accepted 7 August 2013

Available online 20 August 2013

\section{Keywords:}

Triops

Lepidurus

Divergence dates

Fossil calibration

Relaxed molecular clock

\begin{abstract}
A B S T R A C T
We used a combined analysis of one nuclear (28S rDNA) and three mitochondrial markers (COI, $12 \mathrm{~S}$ rDNA, 16S rDNA) to infer the molecular phylogeny of the Notostraca, represented by samples from the six continents that are inhabited by this group of branchiopod crustaceans. Our results confirm the monophyly of both extant notostracan genera Triops and Lepidurus with good support in model based and maximum parsimony analyses. We used branchiopod fossils as a calibration to infer divergence times among notostracan lineages and accounted for rate heterogeneity among lineages by applying relaxed-clock models. Our divergence date estimates indicate an initial diversification into the genera Triops and Lepidurus in the Mesozoic, most likely at a minimum age of 152.3-233.5 Ma, i.e., in the Triassic or Jurassic. Implications for the interpretation of fossils and the evolution of notostracan morphology are discussed. We further use the divergence date estimates to formulate a biogeographic hypothesis that explains distributions of extant lineages predominantly by overland dispersal routes. We identified an additional hitherto unrecognised highly diverged lineage within Lepidurus apus lubbocki and three additional previously unknown major lineages within Triops. Within $T$. granarius we found deep differentiation, with representatives distributed among three major phylogenetic lineages. One of these major lineages comprises $T$. cancriformis, the $T$. mauritanicus species group and two hitherto unrecognised $T$. granarius lineages. Samples that were morphologically identified as $T$. granarius diverged from the most basal nodes within this major lineage, and divergence dates suggested an approximate age of 23.749.6 Ma for T. cancriformis, indicating the need for a taxonomic revision of Triassic and Permian fossils that are currently attributed to the extant $T$. cancriformis. We thus elevate $T$. cancriformis minor to full species status as Triops minor Trusheim, 1938 and include in this species the additional Upper Triassic samples that were attributed to $T$. cancriformis. We further elevate T. cancriformis permiensis to full species status as Triops permiensis Gand et al., 1997.
\end{abstract}

(c) 2013 Elsevier Inc. All rights reserved.

\section{Introduction}

The Notostraca (tadpole shrimp) represent a group of branchiopod crustaceans that has existed since at least the late Devonian (Garrouste et al., 2012). At least one of its genera, namely Triops Schrank, 1803, appears to have attained a morphology indistinguishable from that of modern forms by the Upper Triassic (Trusheim, 1938). Due to this similarity to modern forms, these Triassic fossils were classified as a subspecies of the extant Triops cancriformis (Trusheim, 1938). This appears to have initiated an

\footnotetext{
* Corresponding author. Address: DNA-Labor, Museum für Tierkunde, Königsbrücker Landstrasse 159, D-01109 Dresden, Germany. Fax: +49 0351 7958414327.

E-mail addresses: M.Korn@gmx.com (M. Korn), rabet@mnhn.fr (N. Rabet), hemantghate@gmail.com (H.V. Ghate), federico.marrone@unipa.it (F. Marrone) Anna.Hundsdoerfer@senckenberg.de (A.K. Hundsdoerfer).
}

unequal treatment of fossil finds: often, Notostraca with a Triopslike telson (without a terminal supra-anal plate) were ascribed to T. cancriformis (Gore, 1986; Gand et al., 1997; Kelber, 1999), whereas fossils bearing a posterior elongation of their telson into a supra-anal plate were always described as new species, either within the extant genus Lepidurus Leach, 1819 (see Barnard, 1929), or more often even within a new genus (Yang and Hong, 1980; Tchernyshev, 1940; Hegna and Ren, 2010). The closest known relatives of the Notostraca are the Kazacharthra Nozohilov, 1957, an extinct group of phyllopods known only from the upper Triassic to the lower Jurassic of Asia (Briggs et al., 1993; Olesen, 2009). Together, they form the Calmanostraca Tasch, 1969. The early Devonian Castracollis wilsonae Fayers and Trewin, 2003 is either placed in the Calmanostraca (Fayers and Trewin, 2003) or is treated as sister group to Calmanostraca (Olesen, 2009).

The taxonomy of the Notostraca has been hampered by the exceptionally high morphological variability typical of the group, 
and by the low number of known morphological characters of taxonomic significance (Longhurst, 1955). This situation led to numerous species descriptions that referred to the morphology of individual specimens rather than to that of diagnosible morphospecies (Longhurst, 1955). This rendered many descriptions useless for practical application and made correct species identification nearly impossible. Thus, the revision of Longhurst (1955) was an important step in the taxonomy of the Notostraca, since he retained only taxonomic entities that clearly could be distinguished. He reduced the number of species to only nine worldwide: Triops cancriformis (Bosc, 1801-1802), Triops granarius (Lucas, 1864), Triops longicaudatus (LeConte, 1846), Triops australiensis (Spencer and Hall, 1896), Lepidurus apus (Linn., 1758), Lepidurus arcticus (Pallas, 1793), Lepidurus lynchi Linder, 1952, Lepidurus bilobatus Packard, 1877 and Lepidurus batesoni Longhurst, 1955. Lynch (1966) redescribed Lepidurus lemmoni Holmes, 1894, treating L. lynchi as a synonym, and redescribed Lepidurus couesii Packard, 1875 (see Lynch, 1972) which had been treated as a synonym of L. apus apus by Longhurst (1955). Based on a preceding molecular study by King and Hanner (1998) and a morphological reinvestigation, Rogers (2001) reinstated Lepidurus packardi Simon, 1886 (treated as a subspecies of $L$. apus by Longhurst, 1955) and described a new species, Lepidurus cryptus Rogers, 2001. In addition, a new Central Asian species, Lepidurus mongolicus Vekhov, 1992 was discovered, leading to nine currently valid species in the genus Lepidurus. Molecular studies have also resulted in the reinstatement of Triops newberryi (Packard, 1871) among American Triops and in a revision of $T$. cancriformis that led to the reinstatement of Triops mauritanicus Ghigi, 1921 and Triops simplex Ghigi, 1921 and to the description of four new species, Triops baeticus Korn, 2010, Triops gadensis Korn and García-de-Lomas, 2010, Triops vicentinus Korn, Machado, Cristo and Cancela da Fonseca, 2010 and Triops emeritensis Korn and Pérez-Bote, 2010 thus raising the number of valid species in the genus Triops to 11 (see Korn et al., 2006, 2010). Several molecular phylogenetic studies have shown the need for further taxonomic revisions due to cryptic diversification, such as in T. granarius (Korn and Hundsdoerfer, 2006), T. australiensis (see data presented in Vanschoenwinkel et al. (2012)) and the subspecies of $L$. apus (Mantovani et al., 2009; Vanschoenwinkel et al., 2012). The latter species has been shown to be non-monophyletic (Mantovani et al., 2009; Vanschoenwinkel et al., 2012).

Previous studies investigating phylogenetic relationships within the Notostraca have typically been restricted geographically (e.g. King and Hanner, 1998; Sassaman et al., 1997; Korn et al., 2010) or taxonomically (e.g. Korn et al., 2006). They also included no more than two DNA markers to infer phylogenies, resulting in poor resolution especially of within-genus topologies (e.g. Vanschoenwinkel et al., 2012; Mantovani et al., 2004; but see Korn and Hundsdoerfer, 2006; Mantovani et al., 2009; Mathers et al., 2013b, for well resolved topologies, the latter two with a combined analysis of three, and seven markers, respectively). Moreover, until recently (see Mathers et al., 2013b), it remained unclear if both extant genera, Triops and Lepidurus, were monophyletic (e.g. Vanschoenwinkel et al., 2012; Mantovani et al., 2004). The most recent estimates for the date of initial divergence into the two genera span an extensive range, from 12.75 to at least $250 \mathrm{Ma}$ BP (Vanschoenwinkel et al., 2012; Mathers et al., 2013b). First attempts to obtain DNA-based estimates for this split (Vanschoenwinkel et al., 2012) and for divergences among lineages within the genera relied on 'molecular clocks' derived from non-branchiopod taxa (Korn et al., 2006; Vanschoenwinkel et al., 2012). The peculiar ecology of the group makes this problematic, since Notostraca, as well as Anostraca, Laevicaudata and Spinicaudata, predominantly inhabit temporary bodies of water and spend most of their lives as a dehydrated dormant stage of the embryo that shows no measurable metabolism and is encysted in a highly protective cover
(Dumont and Negrea, 2002) where it may remain for decades until re-flooding of the habitat occurs (e.g. Straka, 2004). This necessarily results in highly reduced long-term gross metabolic rates and longer effective generation times in these taxa, and hence it is probable that their rates of molecular evolution differ from those of other arthropods that lack such prolonged dormant stages (for a review of factors affecting rates of molecular evolution, see Bromham and Penny, 2003).

In the present study, we use a combined analysis of one nuclear and three mitochondrial markers to infer the molecular phylogeny of representative notostracan samples from all six continents that are inhabited by this group of branchiopod crustaceans. We then use non-notostracan branchiopod fossils to calibrate divergence times among notostracan lineages based on molecular data.

\section{Materials and methods}

\subsection{Taxon sampling}

For the present study, we aimed to acquire representative samples of as many major phylogenetic lineages of Notostraca as possible. For the genus Lepidurus, it was unfortunately not possible to obtain fresh samples of $L$. batesoni and L. mongolicus. Both have been collected only once, the former in 1911 from an unknown site possibly located in Kazakhstan (the species is known from only three male specimens, see Longhurst, 1955), the latter in 1975 from a remote locality (Lake Ulan-Nur) in the Gobi desert (Vekhov, 1992).

Tissue vouchers were deposited in the tissue collection of the Museum of Zoology (Museum für Tierkunde), Senckenberg Dresden (Germany) under the MTD-TW numbers listed in Table 1. Sequences of an Australian sample (Triops australiensis) and of a specimen from the Austrian commercial kit ( $T$. cancriformis cancriformis) already available in GenBank were also included in the phylogenetic analyses (see Table 1; only GenBank sequences published until December 2012 were considered).

\subsection{Determination of specimens}

Species determination followed the keys by Longhurst (1955) and Rogers (2001) and the characters given by Sassaman et al. (1997) and Korn et al. (2006). One sample from Bolivia could not be determined morphologically because it had not reached maturity.

\subsection{DNA extraction, PCR amplification and sequencing}

For DNA extraction we followed Korn et al. (2006). Cytochrome c oxidase I (COI) was amplified using the primer pair LCO1490 (forward) - HCO2198 (reverse) of Folmer et al. (1994). Each PCR was performed with 1-5 $\mu$ l of DNA extraction in a $20 \mu$ l volume [ $1 \mu \mathrm{l}$ of each primer at $10 \mu \mathrm{M}, 0.4 \mu \mathrm{l}$ of dNTP-mix at $10 \mathrm{mM}$ of each $\mathrm{dNTP}$, and one unit of Taq polymerase (Bioron DFS Taq, Ludwigshafen, Germany), $2 \mu$ l PCR buffer $10 \times$ incl. $25 \mathrm{mM} \mathrm{MgCl}_{2}$, ultra pure $\mathrm{H}_{2} \mathrm{O}$ ]. Cycler settings were an initial $94^{\circ} \mathrm{C}$ for $4 \mathrm{~min}, 35-40$ cycles of $94^{\circ} \mathrm{C}$ for $30 \mathrm{~s}, 45-50{ }^{\circ} \mathrm{C}$ for $45 \mathrm{~s}, 72^{\circ} \mathrm{C}$ for $1 \mathrm{~min}$ and a final elongation of $72{ }^{\circ} \mathrm{C}$ for $10 \mathrm{~min}$. Subsequent laboratory steps for COI, as well as PCR amplification and sequencing of $12 \mathrm{~S}, 16 \mathrm{~S}$ and $28 \mathrm{~S}$ rDNA fragments followed Korn and Hundsdoerfer (2006) and Korn et al. (2010).

\subsection{Generation of datasets and sequence alignments}

Representatives of six branchiopod genera were used as outgroups to the notostracan samples for our main phylogenetic 
Table 1

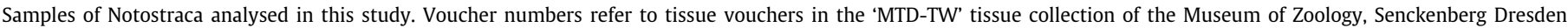

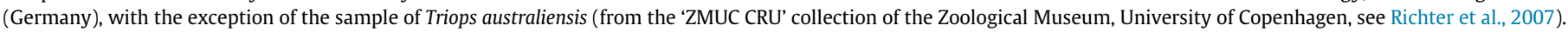

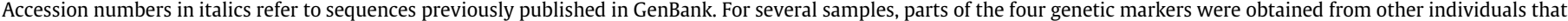

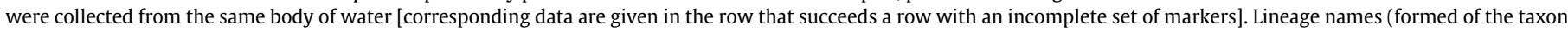
name and a number) refer to clearly diverged clades identified within morphospecies by molecular methods.

\begin{tabular}{|c|c|c|c|c|c|c|}
\hline \multirow[t]{2}{*}{ Taxon or lineage name } & \multirow[t]{2}{*}{ Origin } & \multirow[t]{2}{*}{ Voucher number } & \multicolumn{4}{|c|}{ Accession numbers } \\
\hline & & & $\mathrm{COI}$ & $12 S$ & $16 S$ & $28 \mathrm{~S}$ \\
\hline Triops granarius 1 & Mongolia & 277 & HF911372 & HF911408 & HF911439 & HF911470 \\
\hline Triops granarius 1 & Mongolia & 278 & HF911373 & HF911409 & HF911440 & HF911471 \\
\hline Triops granarius 2 & Japan & 474 & HF911374 & AM269424 & AM269434 & AM269445 \\
\hline Triops granarius 3 & Namibia & 107 & HF911375 & AM269422 & AM269432 & AM269443 \\
\hline Triops granarius 4 & India & 4611 & HF911376 & HF911410 & HF911441 & HF911472 \\
\hline Triops granarius 5 & Tunisia & 43 & HF911377 & AM269418 & AM269428 & AM269439 \\
\hline Triops granarius 5 & Tunisia & 88 & HF911378 & AM269421 & AM269431 & AM269442 \\
\hline Triops granarius 6 & India & 4610 & HF911379 & HF911411 & HF911442 & HF911473 \\
\hline Triops granarius 7 & Namibia (Sossusvlei) & 45 & HF911380 & HF911412 & HF911443 & HF911474 \\
\hline Triops granarius 7 & Namibia (Sossusvlei) & 46 & HF911381 & HF911413 & HF911444 & - \\
\hline Triops granarius 7 & Namibia (Sossusvlei) & 44 & - & - & - & HF911475 \\
\hline Triops granarius 8 & Morocco & 285 & HF911382 & HF911414 & HF911445 & HF911476 \\
\hline Triops granarius 8 & Morocco & 133 & HF911383 & HF911415 & HF911446 & HF911477 \\
\hline Triops granarius 8 & Morocco & 284 & HF911384 & HF911416 & HF911447 & HF911478 \\
\hline Triops granarius 9 & Niger & 2597 & HF911385 & HF911417 & HF911448 & HF911479 \\
\hline Triops granarius 9 & Mauritania & 2600 & HF911386 & HF911418 & HF911449 & HF911480 \\
\hline Triops granarius 9 & Mauritania & 3329 & HF911387 & HF911419 & HF911450 & HF911481 \\
\hline Triops c. cancriformis & Serbia & 253 & FN691432 & AM184170 & AM183850 & HF911482 \\
\hline Triops c. cancriformis & Austria & 51 & FN691431 & AM269414 & AM183821 & AM269435 \\
\hline Triops mauritanicus & Morocco & 138 & FN691440 & AM184178 & AM183899 & HF911483 \\
\hline Triops mauritanicus & Morocco & 37 & FN691442 & - & - & - \\
\hline Triops mauritanicus & Morocco & 4 & - & AM184176 & AM183876 & HF911484 \\
\hline Triops simplex & Morocco & 146 & FN691438 & AM184174 & AM183871 & HF911485 \\
\hline Triops longicaudatus & Kansas, USA & 479 & HF911388 & AM269415 & AM269425 & AM269436 \\
\hline Triops longicaudatus & Japan & 3063 & HF911389 & HF911420 & - & - \\
\hline Triops longicaudatus & Japan & 3187 & - & - & HF911451 & HF911486 \\
\hline Triops newberryi & USA? ${ }^{\mathrm{b}}$ & 258 & HF911390 & HF911421 & HF911452 & - \\
\hline Triops newberryi & USA ${ }^{\mathrm{b}}$ & 281 & - & - & - & HF911487 \\
\hline Triops sp. & Bolivia & 4963 & HF911391 & HF911422 & HF911453 & HF911488 \\
\hline Triops australiensis & Australia & 9940 & $E F 189677$ & AY050646 & EF189616 & EF189662 \\
\hline Triops sp. & Australia (comm. kit) & 4950 & HF911392 & HF911423 & HF911454 & HF911489 \\
\hline Triops sp. & Niger & 2598 & HF911393 & HF911424 & HF911455 & HF911490 \\
\hline Lepidurus apus apus & Poland & 482 & HF911394 & HF911425 & HF911456 & HF911491 \\
\hline Lepidurus apus lubbocki 1 & Latium, Italy & 291 & HF911395 & HF911426 & HF911457 & HF911492 \\
\hline Lepidurus apus lubbocki 1 & Latium, Italy & 121 & HF911396 & HF911427 & HF911458 & - \\
\hline Lepidurus apus lubbocki 1 & Latium, Italy & 119 & - & - & - & HF911493 \\
\hline Lepidurus apus lubbocki 2 & Israel & 655 & HF911397 & HF911428 & - & - \\
\hline Lepidurus apus lubbocki 2 & Israel & 653 & - & - & HF911459 & HF911494 \\
\hline Lepidurus apus viridis & Australia & 3375 & HF911398 & HF911429 & - & HF911495 \\
\hline Lepidurus apus viridis & Australia & 3335 & - & - & HF911460 & - \\
\hline Lepidurus bilobatus & Colorado, USA & 480 & HF911399 & HF911430 & HF911461 & HF911496 \\
\hline Lepidurus lemmoni & Alberta, Canada & 293 & HF911400 & HF911431 & HF911462 & HF911497 \\
\hline Lepidurus lemmoni & Alberta, Canada & 292 & HF911401 & HF911432 & HF911463 & HF911498 \\
\hline Lepidurus lemmoni & Oregon, USA & 3379 & HF911402 & HF911433 & HF911464 & HF911499 \\
\hline Lepidurus arcticus & Norway & 3070 & HF911403 & HF911434 & HF911465 & - \\
\hline Lepidurus arcticus & Norway & 3071 & HF911404 & HF911435 & HF911466 & - \\
\hline Lepidurus arcticus & Norway & 3072 & - & - & - & HF911500 \\
\hline Lepidurus arcticus & Svalbard & 3066 & HF911405 & HF911436 & HF911467 & HF911501 \\
\hline Lepidurus couesii & Alberta, Canada & 2051 & HF911406 & HF911437 & HF911468 & HF911502 \\
\hline Lepidurus sp. & Apulia, Italy & 2042 & HF911407 & HF911438 & HF911469 & - \\
\hline Lepidurus sp. & Apulia, Italy & 2041 & - & - & - & HF911503 \\
\hline
\end{tabular}

a This sequence was accidently attributed to the Triops, INC. commercial kit by Korn and Hundsdoerfer (2006).

b Sample from German commercial kit 'T. australiensis', obtained from Stephan Torske; determination relied on morphology and a comparison to existing GenBank sequences.

analyses and divergence time estimation (additional outgroups were used for comparative divergence time estimation with multiple calibration points, see Section 2.6). Corresponding sequences were retrieved from GenBank (accession numbers listed in consecutive order: COI, 12S, 16S, 28S): (1) Anostraca: Branchinella occidentalis (EF189664, AF494485, EF189600, AY744895), Parartemia (AF209059, AF494484, EF189613, EF189656; 12S, 16S, 28S: Parartemia minuta, COI: Parartemia contracta). (2) Spinicaudata: Caenestheria lutraria (EF189665, EF189597, EF189601, EF189639), Leptestheria dahalacensis (EF189670, AF494476, EF189606, EF189648), Limnadopsis birchii (HQ717759, AF494472, EF189610,
EF189652), Imnadia yeyetta (EF189668, AY009487, EF189605, EF189646). Multiple sequence alignment was performed using webPRANK (Löytynoja and Goldman, 2010) with the 'trust insertions' option '+F' of PRANK. This phylogeny-aware algorithm with 'permanent' insertions recognises insertions and deletions as distinct evolutionary events, thus avoiding systematic bias created by conventional multiple sequence alignment methods that overestimate substitution rates (Löytynoja and Goldman, 2008). This software is among the most accurate programs for multiple sequence alignment of nucleotide data as well as inference of guide trees and it clearly outperforms the traditional programs for gap 
placement (Löytynoja and Goldman, 2008; Dessimoz and Gil, 2010). Guide trees were generated by the program webPRANK. For COI, 'GapRate' was set to 0.01 and 'GapLength' to 3.

Because the terminal part of the 12S sequence 'AY 050646' of Triops australiensis could not be reliably aligned with any other notostracan sequence, only the first $355 \mathrm{BP}$ of this sequence were included in the analyses. Similarly, the terminal $14 \mathrm{BP}$ of the $12 \mathrm{~S}$ sequence from Caenestheria lutraria (EF189597), which is shorter than the other $12 \mathrm{~S}$ sequences in our alignment, were displaced to the terminal section of the alignment. Since this displacement almost certainly represents an artefact, these 14 BP were also excluded from analyses. Alignments of the four molecular markers were appended in BioEdit version 7.1.3.0 (Hall, 1999) prior to phylogenetic analyses.

For our main analyses, we considered only representatives of Anostraca and Spinicaudata as suitable outgroup taxa, because both share similar molecular evolutionary rates with the ingroup and are thus less likely to produce artefacts like those caused by 'long branch attraction'. Nevertheless, although Anostraca and Spinicaudata apparently represent the most suitable among the available outgroup taxa, they still show high genetic divergences from the Notostraca (close relatives of the Notostraca are known from fossils only, see Section 1), so that the inclusion of their sequences still leads to an increased risk of alignment errors. Thus, two additional taxon-subsets were analysed separately for comparison to the complete taxon set including sequences of Notostraca, Anostraca and Spinicaudata (hereafter referred to as 'Notostraca taxon set'). The first was a taxon subset comprising all Triops samples, with five Lepidurus samples (MTD-TW 655, 291, 482, 293 and 3066, see Table 1) as outgroup ('Triops taxon set'). The second was a taxon subset with all Lepidurus samples and five Triops samples (MTD-TW 277, 2598, 4950, 46 and 2597, see Table 1) as outgroup ('Lepidurus taxon set'). Alignment methods for both taxon subsets were carried out as described above. The taxon subsets thus comprise rather closely related lineages, leading to a lowered risk of artefacts in tree topologies due to alignment errors.

In addition to datasets for nucleotide sequences of the four molecular markers, we generated datasets that also included information from the gaps in the nucleotide sequence alignments. These gap characters were added to the nucleotide sequence alignments as an additional binary coded data partition that was generated by applying Simple Indel Coding (Simmons and Ochoterena, 2000) implemented in SeqState version 1.4.1 (Müller, 2005). In total, six datasets were generated (three taxon sets, each with and without additional gap data), each of which was analysed separately for phylogenetic inference.

The resulting alignment of the Notostraca taxon set had a length of $3241 \mathrm{BP}$, including 773 variable characters within the ingroup, of which 683 characters were parsimony informative (values obtained in PAUP* 4.0b10, Swofford, 2003). The corresponding gap dataset consisted of 298 characters, of which 113 characters were variable within the ingroup and 67 were parsimony informative, resulting in a maximum of 750 parsimony informative characters (within the ingroup) included in a single analysis.

\subsection{Phylogenetic analyses}

Each of the six datasets (see Section 2.4) was analysed using maximum likelihood (ML), Bayesian analysis and maximum parsimony (MP). For ML analyses the program RAxML 7.3.0 (Stamatakis, 2006) was operated via raxmlGUI version 1.0 (Silvestro and Michalak, 2011). Settings were ML+ thorough bootstrap, 100 runs, 1000 replicates, a GTR model of substitution with a GAMMA (Yang, 1994) model of rate heterogeneity among sites and a proportion of invariable sites (this option was chosen because modelling the parameter 'invariable sites' was recommended by the best-fit models obtained for COI, see below). Datasets were partitioned by gene. Multiple sequences were defined as outgroups according to the taxon sets.

MrBayes version 3.2.0 (Ronquist et al., 2012) was used for Bayesian analyses. Datasets were partitioned by gene (evolutionary models as specified below, but parameter values were estimated: no priors) and the binary coded gap data were treated as a separate partition (model settings: 'rates = equal, $\operatorname{coding}=$ variable'). The settings for the Bayesian analyses were two runs with four chains of 1,000,000 generations, sampling every 500 generations, and a burn-in fraction of $3 \%$ (Triops taxon set, nucleotides), 4\% (Notostraca taxon set, nucleotides; Triops taxon set, nucleotides and gap data), $5 \%$ (Lepidurus taxon set) or $6 \%$ (Notostraca taxon set, nucleotides and gap data); the burn-in fractions were determined visually upon application of the 'sump' command in MrBayes. For all analyses, standard deviation of split frequencies reached values $\leqslant 0.002$, and values of the Potential Scale Reduction Factor (PSRF) were between 1.0 and 1.018 for all parameters, thus indicating that runs had converged and a good sample from the posterior probability distribution was obtained for each analysis. This was further confirmed by additional convergence diagnostics obtained by the program AWTY (Nylander et al., 2008). For each of the analyses, we plotted split frequencies of first versus second runs (via the "compare" function) against each other, and produced graphs of cumulative split frequencies of the 20 most variable splits (or, for the Lepidurus taxon set, all 17 splits; data not shown). Furthermore, the symmetric tree-difference score (Penny and Hendy, 1985) as implemented in AWTY ('SymDiff' command available within the 'Var' function, executed with default settings) was used to compare topological differences of phylogenetic trees obtained within and among runs.

Best-fit models were obtained with jModelTest version 0.1.1 (Posada, 2008) by use of the Bayesian information criterion (BIC); jModelTest uses PhyML (Guindon and Gascuel, 2003) for likelihood calculations. Best-fit models were: TPM2uf $+\mathrm{I}+\mathrm{G}$ for COI, $\mathrm{TPM} 2 \mathrm{uf}+\mathrm{G}$ for $12 \mathrm{~S}$, TPM3 $\mathrm{uf}+\mathrm{G}$ for $16 \mathrm{~S}$, and $\operatorname{TrN}+\mathrm{G}$ for $28 \mathrm{~S}$ for the Notostraca taxon set, and TPM3uf $+\mathrm{I}+\mathrm{G}$ for COI, as well as $\mathrm{HKY}+\mathrm{G}$ for $28 \mathrm{~S}$ for both the Triops taxon set and the Lepidurus taxon set (12S and $16 \mathrm{~S}$ models as above); parameter values can be obtained from the first author upon request.

MP analyses were performed in PAUP ${ }^{*} 4.0 b 10$ (Swofford, 2003), with a heuristic search using the setting 'addition sequence $=$ closest'. As a measure of branch support, bootstrap values were calculated with MP in PAUP ${ }^{*}$ using 1000 replicates and a heuristic search with settings as in the main analyses.

SeqVerter version 2.0.4.6 (GeneStudio Inc., 2011) was used to interconvert data files between different file formats.

\subsection{Divergence time estimation}

BEAST version 1.7.2 (Drummond et al., 2012) was used for inferring divergence times. For this purpose, a reduced version of the 'Notostraca taxon set' was generated that comprises all outgroup sequences of Anostraca and Spinicaudata as listed above, and a representative subset of notostracan sequences (mainly reduced by excluding some closely related conspecific sequences. The divergence time between Triops longicaudatus and T. newberryi was not dated because they likely form a case of introgression, as inferred from comparison of results from allozymes in Sassaman et al., 1997, with results from mitochondrial markers, e.g. in Vanschoenwinkel et al., 2012). We applied the uncorrelated lognormal relaxed clock model (Drummond et al., 2006) to account for rate heterogeneity among lineages. The Yule process (Gernhard, 2008) was selected as tree prior for the model of speciation, assuming a constant speciation rate for each lineage and we applied the approximate continuous time Markov chain 'CTMC' rate reference 
prior (Ferreira and Suchard, 2008). The dataset was partitioned by gene. Base frequencies, site heterogeneity models, substitution models and clock models were unlinked across data partitions. We applied the GTR + G to $12 \mathrm{~S}, 16 \mathrm{~S}$ and $28 \mathrm{~S}$ and GTR + I + G to $\mathrm{COI}$, referring to recommendations obtained by jModelTest (see Section 2.5). A random starting tree was chosen as the tree model.

Since the validity of known notostracan fossils for inferring the timing of the split into the genera Triops and Lepidurus is presently under debate (Hegna and Ren, 2010), we used instead the split into the orders Notostraca and Spinicaudata for calibrating the phylogenetic tree (both taxa have by far the most complete fossil record among branchiopod lineages, e.g. Tasch, 1969). The early Devonian (Pragian) Rhynie chert fossil Castracollis wilsonae was chosen for inferring the minimum age of the last common ancestor of Notostraca and Spinicaudata (see Section 4.1). The Pragian stage reaches from $407.6( \pm 2.6)$ to $410.8( \pm 2.8)$ million years before present (Ma BP; Cohen et al., 2012). Thus, the corresponding node was given a normally distributed age prior of $407.6 \mathrm{Ma}( \pm 1.3 \mathrm{stdev}$; i.e. representing the lower boundary of the Pragian with its mean and confidence interval as defined by Cohen et al., 2012). For comparison, a separate and more conservative (see Section S.3.2) analysis was performed that assumed a node age for the split into Notostraca and Spinicaudata of $358.9 \mathrm{Ma}( \pm 0.2 \mathrm{stdev})$. This assignment used the minimum age of the oldest known notostracan fossils, which were recovered from a late Devonian (Upper Famennian) deposit (Garrouste et al., 2012, see associated electronic supplement for a photographic documentation of the notostracan fossils referred to). The Famennian spans $358.9( \pm 0.4)-372.2( \pm 1.6)$ Ma (see Cohen et al., 2012). Furthermore, in order to assess the potential effect of choosing multiple fossil calibration points within the outgroup we performed an additional analysis in BEAST (version 1.7.4) that also included sequences of Laevicaudata and Cladoceromorpha. Since both of these groups show substitution rates that differ considerably from those found in Notostraca and Spinicaudata, methods had to be modified for this comparative analysis. We used a topologically constrained guide tree in webPRANK (for 12S and 16S) in order to reduce the risk of alignment errors, and applied a 'Random Local Clock' model (Drummond and Suchard, 2010) to the 12S, 16S and $28 \mathrm{~S}$ data partitions in BEAST because this model allows for multi-modal distributions of 'clock rates'. In total, minimum age estimates inferred from fossils were applied to six calibration points in this analysis (for details, see Supplementary methods, Section S.1).

MCMC analyses were run for 20 million generations and parameters were sampled every 1000 generations. For each of the two analyses (using different age calibration information), LogCombiner (included in the BEAST software package) was used to combine data from three independent MCMC runs in order to obtain Effective Sample Size (ESS) values $>200$ for all notostracan and spinicaudatan lineages (all lineages corresponding to nodes 1-30 in Tables 2 and 3 were defined as taxon sets in BEAST to obtain parameters for each node separately). A burn-in of $10 \%$ of the sampled trees was discarded from each run. ESS values were reviewed in the program TRACER version 1.5 (Rambaut and Drummond, 2009), as were traces and distributions of the posterior and other parameters.

In addition, divergence dates were obtained separately for each of the three mitochondrial markers by application of published 'molecular clocks' in order to assess the magnitude of deviation from divergence dates that were obtained by calibration with branchiopod fossils. For this purpose, additional spinicaudatan and notostracan sequences available in GenBank were included in the analyses (see supplement for a list of included sequences and for alignment methods). Divergence date estimates were derived from mean distances between taxonomic groups, calculated with correction methods that followed those used in studies from which the 'molecular clocks' were obtained. Distances were calculated in PAUP' (for ML corrected distances) and in MEGA version 4 (Tamura et al., 2007; for remaining correction methods). We applied 'molecular clocks' of $1.4 \%$ pairwise sequence divergence/Ma (Knowlton and Weigt, 1998; calibrated by the divergence of snapping shrimp in the genus Alpheus at $3 \mathrm{Ma} \mathrm{BP}$ ) and of $0.95 \%$ pairwise sequence divergence/Ma (mean value for ark shells, Arcidae, inferred from Marko, 2002) to COI. To $12 \mathrm{~S}$ we applied $0.07 \%$ divergence/lineage/Ma, i.e. $0.14 \%$ pairwise sequence divergence/Ma (Simon et al., 1996; calibrated via the split into Drosophila subgenera at 30-60 Ma BP) and the $12 \mathrm{~S}$ rate (0.489 substitutions/site/billion years) and calibration method described by Lynch and Jarrell (1993). However, for our divergence date estimation, we modified their 'method 2' by replacing ' $I_{i j}$ ' (=fraction of shared nucleotides between two sequences $i$ and $j$ ) by ' 1 - (mean p-distance between lineages $i$ and $j$ )' and accordingly, we used average nucleotide frequencies of lineage $i$, and $j$, respectively, to infer the asymptotic identity for each of the two lineages. For divergence dating in the $16 \mathrm{~S}$ gene, we applied 'clock rates' of $0.53 \% / \mathrm{Ma}$ (Stillman and Reeb, 2001; calibrated by the divergence of porcelain crabs, genus Petrolisthes, at $3 \mathrm{Ma} \mathrm{BP}$ ), of $0.02-0.04 \% / \mathrm{Ma}, 0.06-0.12 \% / \mathrm{Ma}$ (inferred from coral genera and families, respectively, see Romano and Palumbi, 1997) and of 0.05-0.2 and 0.07\%/Ma (clocks calibrated by the divergence between Drosophila species, and between Aedes and Drosophila, respectively, as presented in Romano and Palumbi, 1997, referring to data from DeSalle et al., 1987).

\section{Results}

\subsection{Phylogeny}

For analyses based on nucleotides, both the Bayesian inference (as implemented in MrBayes and BEAST) and maximum likelihood (ML) calculations resulted in identical tree topologies of ingroup sequences for all three taxon sets (i.e. Notostraca, Triops, and Lepidurus taxon sets). The inclusion of gap characters resulted in a different position of Triops newberryi in the Bayesian inference $50 \%$ majority-rule trees (Notostraca and Triops taxon sets), as a sister group to the T. longicaudatus samples (instead of grouping within the latter species). This change in topology is predominantly caused by two differences (involving indel positions in the alignment) between $28 \mathrm{~S}$ sequences of $T$. longicaudatus and T. newberryi. Maximum likelihood analyses resulted in topologies identical to those obtained without inclusion of gap characters. Topologies resulting from maximum parsimony (MP) analyses differed from the ML trees with respect to the position of two samples (see below).

Our results confirm a sister group relationship of the genera Triops and Lepidurus (Fig. 1), with good support for the monophyly of these two genera [node support: 100/1.0/100 for Lepidurus and 96/ 1.0/100 for Triops (ML bootstrap/ Bayesian posterior probabilities/ MP bootstrap) obtained from the analysis of nucleotides and gap characters; nodes 3 and 12, Table 2]. Regarding Triops, our present results demonstrate that the diversity within $T$. granarius has hitherto been dramatically underestimated (compare also Korn and Hundsdoerfer, 2006) and that this morphospecies is indeed paraphyletic with respect to the remaining congeneric species, forming the major component of the genus Triops. Among the samples that can morphologically be clearly attributed to this species, samples from Sossusvlei, Namibia ('T. granarius 7', Fig. 1, Table 1) together with a sample from India ('T. granarius 6') form a hitherto unknown major lineage (ML and Bayesian inference) in Triops. In addition, samples of $T$. granarius from northwestern Africa (' $T$. granarius 8 and 9') represent early diverged forms within the lineage that includes T. cancriformis, T. mauritanicus and T. simplex. Although 


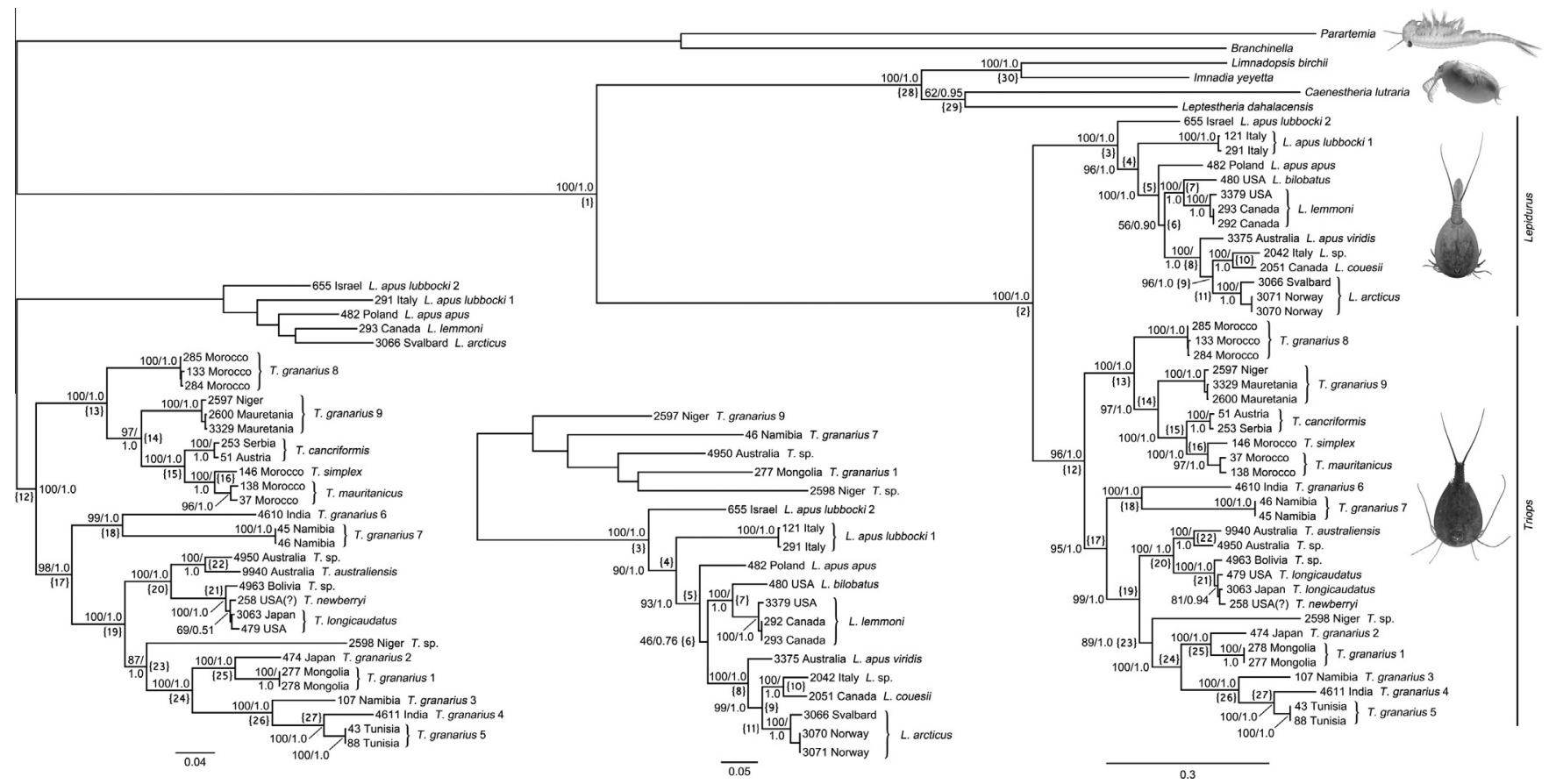

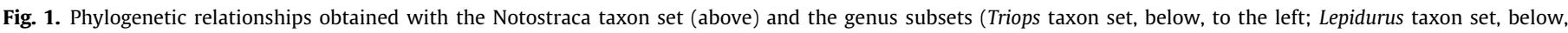

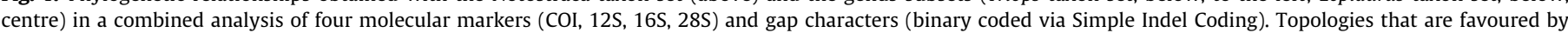

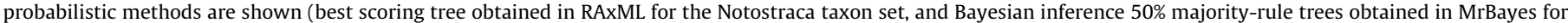

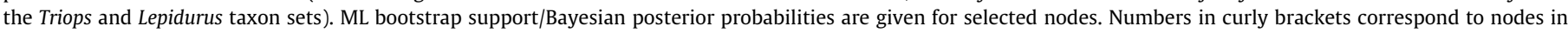
Tables 2 and 3 and to node numbers in Fig. 2.

Table 2

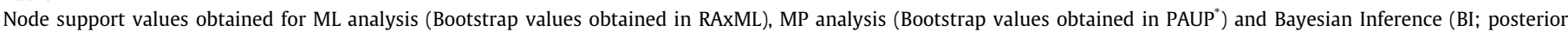

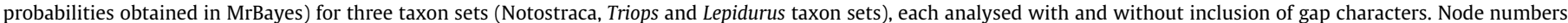

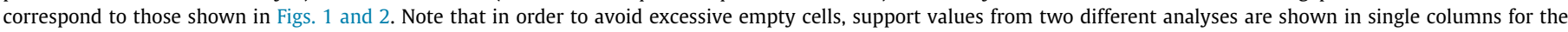
Triops and Lepidurus taxon sets.

\begin{tabular}{|c|c|c|c|c|c|c|c|c|c|c|c|c|}
\hline \multirow[t]{3}{*}{ Node } & \multicolumn{6}{|c|}{ Notostraca taxon set } & \multicolumn{6}{|c|}{ Triops (nodes 12-27) or Lepidurus (nodes 3-11) taxon set, respectively } \\
\hline & \multicolumn{3}{|c|}{ Nucleotides } & \multicolumn{3}{|c|}{ Nucleotides + gap characters } & \multicolumn{3}{|c|}{ Nucleotides } & \multicolumn{3}{|c|}{ Nucleotides + gap characters } \\
\hline & $\mathrm{BI}$ & ML & MP & $\mathrm{BI}$ & ML & MP & $\mathrm{BI}$ & ML & MP & $\mathrm{BI}$ & ML & MP \\
\hline 1 Notostraca + Spinicaudata & 1.00 & 100 & 100 & 1.00 & 100 & 100 & - & - & - & - & - & - \\
\hline 2 Notostraca & 1.00 & 100 & 100 & 1.00 & 100 & 100 & - & - & - & - & - & - \\
\hline 3 Lepidurus & 1.00 & 100 & 100 & 1.00 & 100 & 100 & 1.00 & 100 & 100 & 1.00 & 100 & 100 \\
\hline 4 & 1.00 & 92 & 61 & 1.00 & 96 & 58 & 0.99 & 88 & 85 & 1.00 & 90 & 89 \\
\hline 5 & 1.00 & 92 & 81 & 1.00 & 100 & 90 & 1.00 & 86 & 85 & 1.00 & 93 & 90 \\
\hline 6 & 0.91 & 52 & 57 & 0.90 & 56 & 63 & 0.75 & 42 & 50 & 0.76 & 46 & 49 \\
\hline 7 L. bilobatus + L. lemmoni & 1.00 & 100 & 95 & 1.00 & 100 & 95 & 1.00 & 100 & 93 & 1.00 & 100 & 93 \\
\hline 8 & 1.00 & 100 & 100 & 1.00 & 100 & 100 & 1.00 & 100 & 100 & 1.00 & 100 & 100 \\
\hline 9 & 1.00 & 98 & 96 & 1.00 & 96 & 96 & 1.00 & 99 & 98 & 1.00 & 99 & 98 \\
\hline 10 L. couesii + L. sp. from Italy & 1.00 & 100 & 100 & 1.00 & 100 & 100 & 1.00 & 100 & 100 & 1.00 & 100 & 100 \\
\hline 11 L. arcticus & 1.00 & 100 & 100 & 1.00 & 100 & 100 & 1.00 & 100 & 100 & 1.00 & 100 & 100 \\
\hline 12 Triops & 0.99 & 74 & 98 & 1.00 & 96 & 100 & 1.00 & 100 & 100 & 1.00 & 100 & 100 \\
\hline 13 & 1.00 & 100 & 100 & 1.00 & 100 & 100 & 1.00 & 100 & 100 & 1.00 & 100 & 100 \\
\hline 14 & 1.00 & 97 & 91 & 1.00 & 97 & 92 & 1.00 & 97 & 94 & 1.00 & 97 & 96 \\
\hline 15 & 1.00 & 100 & 100 & 1.00 & 100 & 100 & 1.00 & 100 & 99 & 1.00 & 100 & 100 \\
\hline 16 T. mauritanicus $+T$. simplex & 1.00 & 100 & 100 & 1.00 & 100 & 100 & 1.00 & 100 & 100 & 1.00 & 100 & 100 \\
\hline 17 & 1.00 & 82 & 86 & 1.00 & 95 & 87 & 1.00 & 98 & 81 & 1.00 & 98 & 84 \\
\hline 18 'T. granarius $6+7$ ' & 1.00 & 97 & 33 & 1.00 & 100 & 78 & 1.00 & 96 & 45 & 1.00 & 99 & 76 \\
\hline 19 & 1.00 & 89 & 44 & 1.00 & 99 & 72 & 1.00 & 99 & 46 & 1.00 & 100 & 79 \\
\hline 20 Australian + American Triops & 1.00 & 100 & 100 & 1.00 & 100 & 100 & 1.00 & 100 & 99 & 1.00 & 100 & 100 \\
\hline 21 American Triops & 1.00 & 100 & 100 & 1.00 & 100 & 100 & 1.00 & 100 & 100 & 1.00 & 100 & 100 \\
\hline 22 Australian Triops & 1.00 & 100 & 99 & 1.00 & 100 & 99 & 1.00 & 100 & 99 & 1.00 & 100 & 98 \\
\hline $23^{\prime} T$. granarius $1-5$ ’ $+T$. sp. from Niger & 1.00 & 73 & 21 & 1.00 & 89 & 33 & 1.00 & 85 & 19 & 1.00 & 87 & 31 \\
\hline 24 'T. granarius $1-5$ ' & 1.00 & 99 & 95 & 1.00 & 100 & 94 & 1.00 & 100 & 97 & 1.00 & 100 & 96 \\
\hline 25 'T. granarius $1+2$ ' & 1.00 & 100 & 100 & 1.00 & 100 & 100 & 1.00 & 100 & 100 & 1.00 & 100 & 100 \\
\hline 26 'T. granarius 3-5' & 1.00 & 100 & 100 & 1.00 & 100 & 100 & 1.00 & 100 & 100 & 1.00 & 100 & 100 \\
\hline 27 'T. granarius $4+5$ ' & 1.00 & 100 & 100 & 1.00 & 100 & 100 & 1.00 & 100 & 100 & 1.00 & 100 & 100 \\
\hline 28 Spinicaudata & 1.00 & 100 & 100 & 1.00 & 100 & 100 & - & - & - & - & - & - \\
\hline 29 Leptestheria + Caenestheria & $<0.5$ & 51 & $<5$ & 0.95 & 62 & $<5$ & - & - & - & - & - & - \\
\hline 30 Limnadopsis + Imnadia & 1.00 & 100 & 100 & 1.00 & 100 & 100 & - & - & - & - & - & - \\
\hline
\end{tabular}


geographically clearly more separated from the latter three species than the Moroccan ' $T$. granarius 8', the lineage ' $T$. granarius 9' (recorded for Niger and Mauritania) forms the sister group to T. cancriformis, T. mauritanicus and T. simplex. Finally, a third cluster of lineages morphologically identified as $T$. granarius (' $T$. granarius $1-5$ '; all previously known lineages of $T$. granarius belong to this cluster, see Korn and Hundsdoerfer, 2006) is positioned in a clade that includes the Australian and American samples of Triops. Within this third cluster of $T$. granarius, Mongolian and Japanese samples (' $T$. granarius 1 and 2 ') form the sister group to a geographically widespread lineage including Namibian, Tunisian and Indian samples ('T. granarius 3-5'). Within this latter lineage, the Namibian sample ('T. granarius 3') is placed as the sister group to Tunisian ('T. granarius 5') and Indian ('T. granarius 4') samples.

In addition to the discovery of new lineages of Triops granarius, we identified a highly diverged, morphologically indeterminate lineage from the Sahara (Triops sp. from Niger). It forms the sister group to ' $T$. granarius 1-5' in all probabilistic analyses. Maximum parsimony analyses place this lineage either in a sister group relationship to 'T. granarius 7' (nucleotides, Notostraca taxon set, and one of two most parsimonious trees of the Triops taxon set), or as sister group to Australian and American Triops plus ' $T$. granarius 1-5' (nucleotides + gap characters, Notostraca taxon set and Triops taxon set; nucleotides, one of two most parsimonious trees of the Triops taxon set).

Within Lepidurus, the morphospecies L. apus has a role similar to that of $T$. granarius in the genus Triops. It also is paraphyletic with respect to the remaining congeneric species, and despite several previous molecular studies dealing with this taxon (e.g. Mantovani et al., 2004, 2009; Vanschoenwinkel et al., 2012), its level of diversification still had been underestimated, as demonstrated by the discovery of a new, highly diverged lineage within $L$. apus lubbocki ('L. apus lubbocki 2'), which occurs in Israel. In all probabilistic analyses, this lineage forms the sister group to the remaining samples of Lepidurus included in the present study. Within the latter, samples of L. apus lubbocki from Latium, Italy ('L. apus lubbocki 1') represent the lineage that diverged from the most basal node, followed by L. apus apus. Within the remaining samples, the North American endemics $L$. bilobatus and $L$. lemmoni form the sister group to a lineage comprising $L$. apus viridis as the sister group to L. arcticus, Lepidurus sp. from Apulia, Italy, and L. couesii. The latter two form a monophyly and are positioned in a sister group relationship to L. arcticus.

Maximum parsimony analysis also identifies the Lepidurus apus lubbocki lineages as the two lineages that diverge from the two most basal nodes observed within our Lepidurus samples, and the topology of the MP trees obtained with the Lepidurus taxon set are identical to those obtained by probabilistic methods. However, in the MP trees obtained with the Notostraca taxon set, the relationship between both $L$. apus lubbocki lineages is either unresolved (nucleotides + gap characters), or the respective positions of both lineages are exchanged (nucleotides; it should be noted that MP bootstrap support is only $36 \%$ for this topology compared to $61 \%$ MP bootstrap support for the topology as obtained by probabilistic methods).

\subsection{Divergence times}

The minimum age for the split into the genera Triops and Lepidurus is placed in the Mesozoic by both analyses performed with BEAST. Calibration with late Devonian Notostraca resulted in an age estimate between 131.5 and 203.1 Ma (95\% HPD range), whereas calibration with Castracollis suggested an age of 152.3$233.5 \mathrm{Ma}$ (95\% HPD range). Only results from the latter calibration are considered further because it corresponds to a more parsimonious interpretation of the fossil record (see Sections 4.1 and S.3.2). Corresponding divergence date estimates for nodes in Fig. 2 are listed in Table 3. Divergence date estimates for the split into Triops and Lepidurus obtained by the comparative analysis that included further fossil calibration points in the outgroup, in

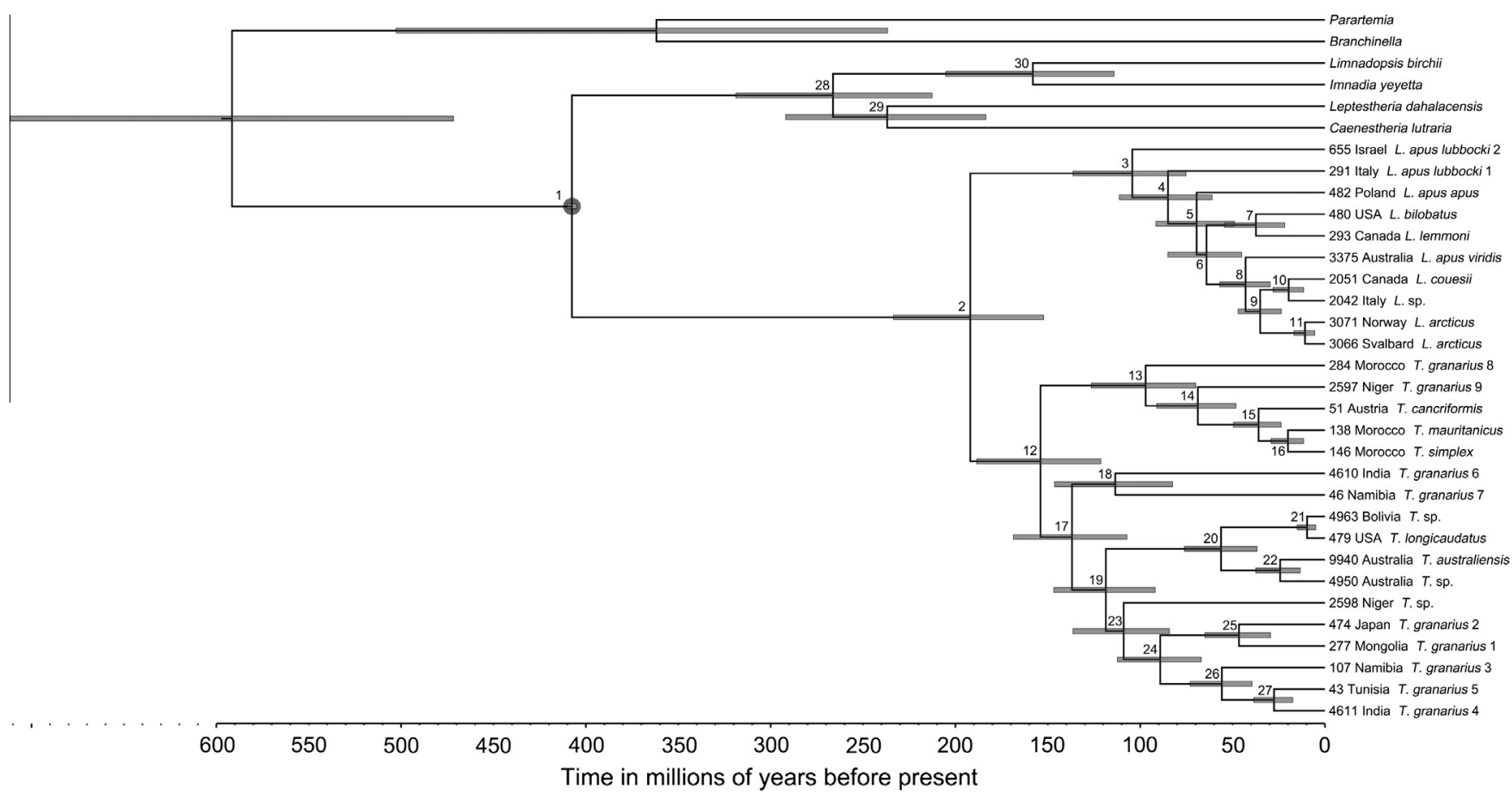

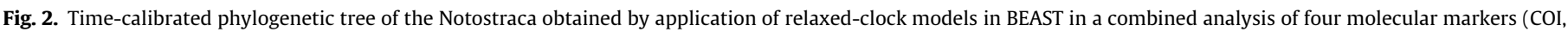

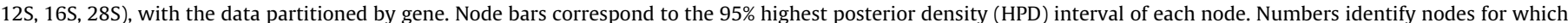

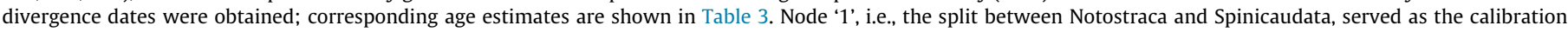
point for the analysis (inferred minimum age of the last common ancestor of both taxa; marked with a filled circle). 
Table 3

Divergence date estimates (given in millions of years) for ingroup nodes in Fig. 2, obtained upon application of relaxed-clock models in BEAST. For the analysis, a node age prior of $407.6 \mathrm{Ma}( \pm 1.3 \mathrm{stdev})$ for node 1 was calibrated with the fossil Castracollis wilsonae Fayers and Trewin, 2003.

\begin{tabular}{|c|c|}
\hline Node & $\begin{array}{l}\text { Divergence date estimate Mean (95\% } \\
\text { HPD) }\end{array}$ \\
\hline 1 Notostraca + Spinicaudata & $407.6(405.1-410.2)$ \\
\hline 2 Notostraca & $192.0(152.3-233.5)$ \\
\hline 3 Lepidurus & $104.3(75.3-136.4)$ \\
\hline 4 & $84.9(61.0-111.3)$ \\
\hline 5 & $69.5(49.0-91.5)$ \\
\hline 6 & $65.4(46.3-87.5)$ \\
\hline 7 L. bilobatus + L. lemmoni & $37.4(21.8-54.4)$ \\
\hline 8 & $42.9(29.6-56.9)$ \\
\hline 9 & $35.1(23.8-47.2)$ \\
\hline 10 L. couesii + L. sp. from Italy & $19.6(11.6-28.1)$ \\
\hline $11 \mathrm{~L}$. arcticus & $10.8(5.6-16.8)$ \\
\hline 12 Triops & $154.0(121.2-188.5)$ \\
\hline 13 & $97.0(69.9-126.4)$ \\
\hline 14 & $68.8(48.1-91.1)$ \\
\hline 15 & $35.9(23.7-49.6)$ \\
\hline $16 T$. mauritanicus $+T$. simplex & $20.0(11.5-29.2)$ \\
\hline 17 & $136.9(107.1-168.7)$ \\
\hline 18 'T. granarius $6+7$ ’ & $113.5(82.4-146.4)$ \\
\hline 19 & $118.6(91.9-146.8)$ \\
\hline 20 Australian + American Triops & $56.2(36.8-76.0)$ \\
\hline 21 American Triops & $9.7(5.0-15.0)$ \\
\hline 22 Australian Triops & $24.3(13.4-37.5)$ \\
\hline $\begin{array}{l}23 \text { 'T. granarius } 1-5 ’+T \text {. sp. from } \\
\text { Niger }\end{array}$ & $109.2(84.1-136.9)$ \\
\hline 24 'T. granarius $1-5$ ' & $89.2(67.0-112.4)$ \\
\hline 25 'T. granarius $1+2$ ' & $46.5(29.4-64.9)$ \\
\hline 26 'T. granarius 3-5' & $55.8(39.5-72.9)$ \\
\hline 27 'T. granarius $4+5$ ' & $27.6(17.5-38.6)$ \\
\hline 28 Spinicaudata & $266.3(212.6-318.8)$ \\
\hline 29 Leptestheria + Caenestheria & $242.3(183.1-307.0)$ \\
\hline 30 Limnadopsis + Imnadia & $158.1(114.2-205.3)$ \\
\hline
\end{tabular}

addition to Castracollis, are presented in Table S1. The corresponding 95\% HPD range of six combined runs was 154.0-260.1 Ma, which is in good agreement with the single calibration point analysis (see above), though with a tendency towards older age estimates. However, age estimates were less stable within and among replicates (a known problem of the 'Random Local Clock' model, Drummond and Suchard, 2010, which we applied to this analysis, see Dornburg et al., 2012), often resulting in lower ESS values, so that we also present results separately for each run. Since the obtained ESS values were lower for the multi-calibration point approach (despite a higher chain length), we will in the following only refer to results obtained by the single calibration point analysis (see Table 3). The earliest diversifications observed within the genera are thus inferred to have occurred at 121.2-188.5 Ma BP (95\% HPD range) for Triops and at 75.3-136.4 Ma BP (95\% HPD range) for Lepidurus (Table 3 ). It is clear that in several major lineages the current taxonomy does not appropriately reflect their differentiation into evolutionary entities that appear to represent cryptic or just unrecognised species that await formal description (e.g. Korn and Hundsdoerfer, 2006). Therefore, it is presently difficult to identify levels of typical inter- and intraspecific divergences. For example, the oldest differentiation observed within Lepidurus (dated at 75.3-136.4 Ma BP, see above) corresponds to the split between samples presently attributed to a single subspecies, i.e. L. apus lubbocki. The highest level of divergence among samples that are likely to retain conspecific status was observed within L. arcticus (between samples from Svalbard and from southern Norway, corresponding to haplogroups ' $A$ ' and ' $B$ ' in Hessen et al., 2004). This split was estimated at an age of approx. 10.8 Ma BP (95\% HPD range 5.6-16.8, node 11 in Table 3). Divergences among 'youngest' recognised species in groups that were revised using modern methods (excluding the American Triops species that appear to be differentiated only in the nuclear genome) are estimated to be approximately twice as old: the split between T. mauritanicus and T. simplex is dated at approx. 20.0 Ma BP (95\% HPD range 11.5-29.2; node 16, Table 3).

Among the genes studied, $12 \mathrm{~S}$ showed the least deviation from clock-like evolution ('ucld.stdev' 0.28; a value of zero would indicate complete lack of variation in substitution rates among branches), $16 \mathrm{~S}$ and COI showed slightly stronger deviation ('ucld.stdev' 0.50) whereas 28S showed a substantial amount of rate heterogeneity among lineages ('ucld.stdev' 1.31). Rates of molecular evolution that were obtained in BEAST are shown in Table 4.

Comparative divergence dates that were obtained by applying published 'molecular clocks' are presented in Table 5. Age estimates varied considerably by taxon groups and the calibration ages that were used to infer the 'molecular clocks'.

\section{Discussion}

\subsection{Choice of fossils for calibration of divergence times}

For our preferred dating of divergence times, we chose the early Devonian Rhynie chert fossil Castracollis wilsonae as the calibration point corresponding to the minimum age of the last common ancestor of Notostraca and Spinicaudata. Castracollis is of Pragian age, 407.6-410.8 Ma BP (Fayers and Trewin, 2003; Cohen et al. 2012). Among all presently known species, this fossil represents the most plausible candidate for a last common ancestor of Notostraca and Spinicaudata because it shares characters with both the notostracan and the diplostracan lineage (Olesen, 2009). However, maximum parsimony analysis of morphological characters suggests that it most likely belongs to the notostracan stem lineage (Olesen, 2009). This would imply an even older age of the last common ancestor of Notostraca and Spinicaudata, i.e., this calibration may actually cause an underestimation of divergence times. Oldest records of Spinicaudata are also from the early Devonian (Tasch, 1969; followed by geographically widespread records from the Middle Devonian and Upper Devonian, Tasch, 1987) so that an early Devonian (i.e. 393.3-419.2 Ma BP, see Cohen et al., 2012; or older) age of the last common ancestor of Notostraca and Diplostraca (including Spinicaudata) appears to be the most likely

Table 4

Substitution rates ('ucld.mean': this parameter represents the mean of the branch rates under the uncorrelated lognormal relaxed clock) and corresponding rates of pairwise sequence divergence (inferred from values of 'ucld.mean'). Data were obtained by our preferred analysis in BEAST (the dataset included samples of Anostraca, Notostraca and Spinicaudata; the split into Notostraca and Spinicaudata was calibrated with the fossil Castracollis wilsonae Fayers and Trewin, 2003).

\begin{tabular}{llll}
\hline Gene & Substitutions/site/Ma Mean (95\% HPD) & $\begin{array}{l}\text { Pairwise sequence } \\
\text { divergence rate Mean }\end{array}$ & $\begin{array}{l}\text { Substitution - and site } \\
\text { heterogeneity model }\end{array}$ \\
\hline COI & $2.62 \mathrm{E}-3(1.86-3.46 \mathrm{E}-3)$ & $0.52 \% / \mathrm{Ma}$ & GTR + Gamma + Invariant Sites \\
$12 \mathrm{~S}$ & $1.03 \mathrm{E}-3(0.78-1.28 \mathrm{E}-3)$ & $0.21 \% / \mathrm{Ma}$ & GTR + Gamma \\
$16 \mathrm{~S}$ & $6.07 \mathrm{E}-4(4.50-7.74 \mathrm{E}-4)$ & $0.12 \% / \mathrm{Ma}$ & GTR + Gamma \\
$28 \mathrm{~S}$ & $2.09 \mathrm{E}-4(1.22-3.12 \mathrm{E}-4)$ & $0.04 \% / \mathrm{Ma}$ & GTR + Gamma \\
\hline
\end{tabular}


Table 5

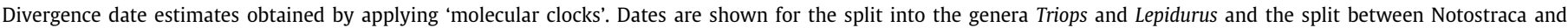

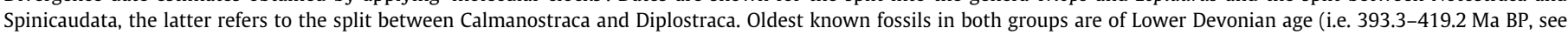

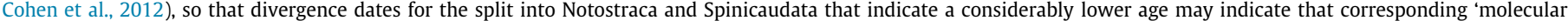
clocks' are not suitable for calibrating divergence dates in both taxa, because they suggest an implausible scenario of repeated independent origins of both groups.

\begin{tabular}{|c|c|c|c|c|c|c|}
\hline \multirow[t]{2}{*}{ Gene } & \multicolumn{2}{|c|}{ Inferred mean age for the split into: } & \multirow{2}{*}{$\begin{array}{l}\text { Clock rate: } \\
\text { (pairwise sequence } \\
\text { divergence) }\end{array}$} & \multirow{2}{*}{$\begin{array}{l}\text { Correction method } \\
\text { applied }\end{array}$} & \multirow[t]{2}{*}{ Calibration age } & \multirow{2}{*}{$\begin{array}{l}\text { Taxa used for } \\
\text { calibration }\end{array}$} \\
\hline & $\begin{array}{l}\text { Triops and } \\
\text { Lepidurus }\end{array}$ & $\begin{array}{l}\text { Notostraca and } \\
\text { Spinicaudata }\end{array}$ & & & & \\
\hline $\mathrm{COI}$ & $92.4 \mathrm{Ma}$ & $141.0 \mathrm{Ma}$ & $1.4 \% / \mathrm{Ma}$ & ML & $3 \mathrm{Ma}$ & Snapping shrimp \\
\hline $\mathrm{COI}$ & $136.2 \mathrm{Ma}$ & $207.9 \mathrm{Ma}$ & $0.95 \% / \mathrm{Ma}^{\mathrm{a}}$ & ML & $\begin{array}{l}\text { 83-118 Мa; 79-89 Мa; 16- } \\
23 \mathrm{Ma}\end{array}$ & Ark shells \\
\hline $12 \mathrm{~S}$ & $120.7 \mathrm{Ma}$ & $251.7 \mathrm{Ma}$ & $0.0978 \% / \mathrm{Ma}$ & $\begin{array}{l}\text { Lynch and Jarrell } \\
\text { (1993) }\end{array}$ & Multiple, ancient & Animal phyla \\
\hline $12 \mathrm{~S}$ & 152.1 Ма & $245.0 \mathrm{Ma}$ & $0.14 \% / \mathrm{Ma}^{\mathrm{b}}$ & Tamura 3-Parameter & 30-60 Ма & Drosophila subgenera \\
\hline $16 S$ & $44.5 \mathrm{Ma}$ & 161.7 Ma & $0.53 \% / \mathrm{Ma}$ & ML & $3 \mathrm{Ma}$ & Porcelain crabs \\
\hline $16 S$ & $50.5-202.0 \mathrm{Ma}$ & $108.5-434.0 \mathrm{Ma}$ & $0.05-0.2 \% / \mathrm{Ma}$ & Uncorrected & $2-60 \mathrm{Ma}$ & Drosophila species \\
\hline $16 S$ & $144.3 \mathrm{Ma}$ & $310.0 \mathrm{Ma}$ & $0.07 \% / \mathrm{Ma}$ & Uncorrected & $200 \mathrm{Ma}$ & Aedes vs. Drosophila \\
\hline $16 S$ & $252.5-505.0 \mathrm{Ma}$ & $542.5-1085.0 \mathrm{Ma}$ & $0.02-0.04 \% / \mathrm{Ma}$ & Uncorrected & 30-60 Ма & Coral genera \\
\hline $16 S$ & $84.2-168.3 \mathrm{Ma}$ & $180.8-361.7 \mathrm{Ma}$ & $0.06-0.12 \% / \mathrm{Ma}$ & Uncorrected & $67-100 \mathrm{Ma}$ & Coral families \\
\hline
\end{tabular}

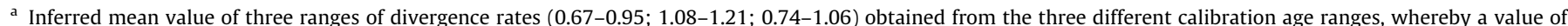
(lower boundary + upper boundary)/2 was used for each obtained range in order to calculate the mean value for all three rate ranges.

$\mathrm{b}$ Maximum average rate referring to the range of the time estimate.

interpretation and therefore will be used in the present study. For discussion of a similar calibration that was applied in a recent study (Mathers et al., 2013a), and for a discussion of our alternative, highly conservative calibration, see Section S.3.

\subsection{Comparison to divergence dates obtained upon application of 'molecular clocks'}

Our age estimate of 152.3-233.5 Ma BP (node 2 in Table 3 ) for the split into Triops and Lepidurus is considerably older than the estimates inferred upon application of available published 'molecular clocks' for non-branchiopod Crustacea (Table 5; see also Section S.4). These 'molecular clocks' would typically have been applied for inferring divergence dates in branchiopods because other available 'molecular clocks' were derived from more distantly related taxa. However, a comparison of the divergence date estimates that are presented in Table 5 suggests that it may generally be more beneficial to choose a 'molecular clock' that was derived from suitable calibration ages rather than choosing 'molecular clocks' from closely related taxa. Indeed, there is growing evidence for a time-dependence of molecular evolutionary rates, with young calibrations yielding elevated rate estimates (Ho et al., 2011).

Vanschoenwinkel et al. (2012) did not appropriately consider this effect when they predominantly applied 'molecular clocks' that were obtained from relatively young calibrations in order to infer the age of the split into Triops and Lepidurus from their $12 \mathrm{~S}$ and COI data sets. They obtained an age estimate of 12.75-55.6 Ma for the divergence between both genera and concluded that, based on the whole range of confirmed 'molecular clocks' in invertebrates, a Mesozoic radiation was highly implausible. The divergence date estimates that we obtained upon application of published 'molecular clocks' are in strong conflict with Vanschoenwinkel et al.'s (2012) results and interpretations. Actually, the clocks we applied suggest divergence dates that are clearly older than those proposed by Vanschoenwinkel et al. (2012), even in cases where the clocks were inferred from identical publications (see Table 5). A comparison suggests that Vanschoenwinkel et al. (2012) did not use the appropriate site heterogeneity and substitution models under which the 'molecular clocks' were calibrated. The magnitude at which this may affect resulting age estimates becomes apparent when comparing divergence dates, rates, and correction methods in Table 5 to those in Table 3 and 4 (more complex correction methods generally result in higher inferred 'clock rates' for a given divergence date). Vanschoenwinkel et al. (2012) further confused values of pairwise sequence divergence with values given in substitutions per site (their 'slowest' rate for COI of $1.2 \%$ per Ma actually was a per-lineage rate, see Caccone and Sbordoni, 2001, so that the rate of $1.4 \%$ sequence divergence per Ma actually would have been the slowest clock they applied). Likewise, the publication that Vanschoenwinkel et al. (2012) refer to as the origin of their ' $12 \mathrm{~S}$ clock' shows a substitution rate of 0.489 /billion years, which would translate into a pairwise sequence divergence of $0.0978 \% / \mathrm{Ma}$ instead of the $0.5 \%$ applied by Vanschoenwinkel et al. (2012). We thus conclude that the age estimates provided by these authors were based upon erroneous methods and should be rejected.

\subsection{Comparison to divergence date estimates inferred from notostracan fossils}

Hegna and Ren (2010) re-evaluated the morphology of Lepidurus batesoni in comparison to the morphology of fossils, thereby revealing uncertainties regarding the monophyletic status of Lepidurus. With the exception of $L$. batesoni (see Longhurst, 1955), adults of all known extant Notostraca show a unique, derived morphology: their first trunk limb bears a highly reduced endopod and endites (especially the fourth and fifth endite) that are strongly elongated compared to relative lengths of endites in subsequent appendages, resulting in an antenna-like appearance (see e.g. Fig. 2A in Longhurst, 1955). Hegna and Ren (2010) stated that all fossil notostracans lacked this differentiation of anterior limbs and concluded that the above described modifications likely were a synapomorphy of a clade of living notostracans, possibly excluding L. batesoni. Accordingly, Hegna (2011) suggested that "virtually the entire fauna of extant notostracans" had a rather recent origin, " $\geqslant 65$ mya" (from the context, it may be inferred that ">" is used here as a synonym for "later than"). The assumptions on which these interpretations were based are, however, in conflict with Trusheim's (1938) findings that suggest that elongated antenna-like endites actually were already present in the Upper Triassic Triops cancriformis minor (approx. age 208.5-228 Ma, see Section S.5).

Our divergence date estimates clearly do not match Hegna's (2011) hypothesis. Even with our alternative divergence dating 
which almost certainly is too conservative (see Section S.3.2), our BEAST analysis indicates the split into Triops and Lepidurus most likely occurred at least twice as long ago as the date suggested by Hegna (2011), at 131.5-203.1 Ma BP (95\% HPD range; see Section 3.2). Our observations actually support a different hypothesis of morphological evolution that would explain the absence of antenna-like endites in the fossils of supra-anal-plate bearing notostracans that appear to have inspired the interpretations of Hegna and Ren (2010; see Tchernyshev, 1940). We identified consistent differences in the morphology of first trunk limbs of Triops and 'Modern Lepidurus' (i.e. as included in the present study; see Section S.2, S.6.1 and Figs. S1-3). These differences, together with a lack of differentiation in the supra-anal-plate (see Section S.6.2) actually suggest that supra-anal-plate bearing notostracans may form a monophyletic group and that modifications in the first trunk limbs may have evolved independently in Triops and in 'Modern Lepidurus'. In the latter, these modifications may thus have occurred later than in Triops. But even following this interpretation in Triops, modified first trunk limbs would likely have first evolved at 121.2-233.5 Ma BP (cumulative range of nodes 2 and 12 , Table 3). Trusheim's (1938) interpretation that the morphology of the Triassic T. cancriformis minor resembled that of extant Triops (see above) thus appears plausible, which supports its present position within the genus Triops.

Mathers et al. (2013b) recently suggested a minimum age of 250 Ma BP for the initial diversification into Triops and Lepidurus. This date comes close to our age estimate of 152.3-233.5 Ma BP (node 2 in Table 3). Mathers et al.'s (2013b) estimate is based on the Permian fossils T. cancriformis permiensis Gand et al., 1997 and $L$. occitaniacus Gand et al., 1997, assuming a monophyly of supra-anal-plate bearing notostracans. However, a careful reevaluation of available information suggests that the oldest reliable record of a notostracan typical of Lepidurus, i.e., with a telson that bears a supra-anal plate, actually is that of the Lower Jurassic L. stormbergensis Haughton, 1924 (see Section S.5 for details). Its age of 190.8-201.3 Ma (see Section S.5) is in line with our minimum age estimate of 152.3-233.5 Ma BP for the split into Triops and Lepidurus. Regarding T. cancriformis permiensis, the available morphological characters do not allow differentiation of this taxon from extant representatives of Triops. Nevertheless, the morphological characters that are preserved in this fossil would also be in line with a possible interpretation as a common ancestor of Triops and Lepidurus (see Section S.5). The Permian fossils (see above) therefore cannot be used to infer a reliable minimum age estimate for the split into Triops and Lepidurus.

Acceptance of the present classification of Triassic and Permian fossils as subspecies of the extant Triops cancriformis would have suggested an even earlier age for the split into Triops and Lepidurus. We discovered representatives of $T$. granarius in three major lineages of Triops, among them lineages ' $T$. granarius 8 and 9', which branch off from the basalmost nodes within the major lineage that includes $T$. cancriformis (and its morphologically similar sister group, represented in the present study by T. mauritanicus and $T$. simplex). This suggests that a morphology typical of $T$. granarius most likely represents the plesiomorphic state within this latter major lineage, which is defined by 'node 13' in Figs. 1 and 2. A comparison with our molecular divergence dating thus suggests that within this lineage, a morphology similar to that of $T$. cancriformis actually may not have evolved much earlier than 90 Ma BP (see node 14 , Table 3 ). Furthermore, the divergence of $T$. cancriformis from its sister group is estimated at 23.7-49.6 Ma in our analysis (node 15, Table 3 ) so that an origin of $T$. cancriformis much earlier than 50 Ma BP appears unlikely. Possible morphological similarities of $T$. cancriformis minor and T. cancriformis permiensis to modern T. cancriformis (see Trusheim, 1938; Gand et al., 1997) therefore should no longer be regarded as synapomorphies, and an interpretation of $T$. cancriformis as a 'living fossil' species of Triassic or Permian origin should be rejected. The taxonomy of corresponding fossils thus needs to be revised.

\subsection{Biogeography}

Throughout this section, we refer to plate tectonic events and their timing as summarised in Sanmartín et al. (2001), Sanmartín and Ronquist (2004) and Bossuyt et al. (2006). Korn et al. (2010) demonstrated that in gonochoric lineages of Notostraca, repeated short-distance dispersal is likely to be the prevailing mechanism during range extensions. Therefore, we regard biogeographic hypotheses that assume multiple trans-oceanic long-distance dispersals of gonochoric notostracan lineages to be unlikely (by contrast, Vanschoenwinkel et al., 2012, suggest an involvement of such dispersals during a radiation into major Triops lineages).

\subsubsection{Biogeography of the genus Triops}

Within Triops, representatives of early diverged lineages are predominantly found on Gondwanan landmasses: among the samples included in the present study, only clades defined by nodes 15 , 21 and 25 (see Fig. 2) include representatives found on nonGondwanan landmasses. The oldest node in the tree that may lead to an exclusively non-Gondwanan clade (i.e. comprising ' $T$. granarius 1 and 2') is node 24 (see Fig. 2), which is dated at a mean age of 89.2 Ma BP (Table 3). Furthermore, the earliest recorded diversification event within the genus is dated at $154.0 \mathrm{Ma} \mathrm{BP}$ (95\% HPD range: $121.2-188.5$, see node 12 , Table 3 ) and is thus likely to have occurred soon after the separation of Pangaea into Laurasia and Gondwana at 160-180 Ma BP. Therefore, the genus Triops (as represented by extant forms) is likely a typical Gondwanan group. Accordingly, divergence patterns and corresponding age estimates of several lineages in the phylogenetic tree may be attributed to the sequential breakup events of the supercontinent Gondwana and to re-connections of Gondwanan to Laurasian landmasses. For example, the divergence of the Australian-American lineage from their African-Asian sister group, dated at 91.9146.8 Ma BP (95\% HPD range, node 19, Table 3) is in agreement with the separation of Australia from Africa at $130-135$ Ma BP, and the divergence between Australian and American Triops at 36.8-76.0 Ma BP (95\% HPD range, node 20, Table 3) corresponds to the breakup of terrestrial connections between Australia and South America (via Antarctica) at 35-52 Ma BP. During this period, favourable climatic conditions resulted in an important faunal and floral exchange between Australia and southern South America, whereas tropical forest is assumed to have formed a massive dispersal barrier between tropical South America and temperate South America (Sanmartín and Ronquist, 2004). The divergence between Southern American and Northern American Triops at 5.015.0 Ma BP (95\% HPD range; node 21, Table 3) corresponds to the age of the reconnection of South and North America at $15 \mathrm{Ma}$ BP that led to the Great American Exchange of faunas (Sanmartín and Ronquist, 2004). We therefore propose an Australian origin of American Triops and a colonisation of North America from temperate South America (see Fig. S.4). An Australian origin of the Australian-American lineage is supported by higher diversity in Australian Triops (in particular, see undetermined lineage from Lake Carey in Vanschoenwinkel et al., 2012).

The split between the lineages 'Triops granarius 6' (India) and ' $T$. granarius 7' (Namibia) at 82.4-146.4 Ma BP (95\% HPD range, node 18 , Table 3 ) comprises the age of the separation of India from Africa at approximately $121 \mathrm{Ma} B P$, so that ' $T$. granarius 6 ' could represent an ancient Indian lineage, i.e. a Gondwanan relict. However, it is not clear if Triops could have survived a phase of tropical humid climate in the early Eocene occurring throughout India (see climatic reconstructions in Scotese, 2012), prior to India's collision 
with Asia. At that time, tropical rainforests were widely distributed in India (Prasad et al., 2009), so that habitats suitable for Notostraca might have been scarse or even completely absent from India. Continuing evolution of the ' $T$. granarius 6 and 7' clade in Africa and colonisation via Asia after the re-establishment of an African-Asian connection via the Arabian plate at 40-45 Ma BP might therefore be regarded a more likely explanation for present distributions (see Fig. S.4). Likewise, the lineages ' $T$. granarius 1 and 2' may have diverged within East Asia during a range expansion following their colonisation of Asia via the Arabian plate. Their estimated mean age of origin at $46.5 \mathrm{Ma} \mathrm{BP}$ (node 25, Table 3) corresponds well to the age of the establishment of the land bridge that connected Africa to Asia (see above). An initial divergence from their African-Indian sister group is likely to have occurred in Southern Africa, as is indicated by the occurrence of an early diverged lineage in Namibia ('T. granarius 3'). This African-Indian lineage seems to have dispersed from southern Africa to northern Africa and to India, accompanied by several diversification events.

\subsubsection{Biogeography of the genus Lepidurus}

All 'Modern Lepidurus' (as included in the present phylogenetic analysis) are known to have lower temperature preferences than Triops, and no fossil species of supra-anal-plate bearing notostracans are reported from low latitudes. Consequently, it is parsimonious to assume that an adaptation to lower temperatures is a synplesiomorphic character within this group. It thus seems unlikely that Lepidurus survived in Africa throughout the Mesozoic and Tertiary. This is supported by the fact that the genus has not been recorded for southern Africa after the Lower Jurassic (Barnard, 1929, note that corresponding fossils were originally placed into the Triassic). The distribution of known representatives of the lineages that diverged from the two most basal nodes within 'Modern Lepidurus' in the central and eastern Mediterranean (see 'L. apus lubbocki 1 and 2', Fig. 2) thus suggest an initial evolution of the group within Europe. While adjacent areas in Africa and on the Arabian plate that are presently inhabited by these lineages likely lacked suitable climatic conditions during the early evolution of this group, climatic conditions in Europe seem to have been favourable for this lineage since its divergence from Triops (see climatic reconstructions in Scotese, 2012; an origin of these lineages in climatically suitable areas of Asia would require independent dispersal of both lineages over considerably longer distances which appears to be less parsimonious). Available distribution records also suggest that L. apus apus s.s., i.e., the sister group to remaining 'Modern Lepidurus' (Fig. 1), likely has a European origin (see Section S.7). The lineage comprising the American endemics L. lemmoni, $L$. bilobatus and almost certainly also $L$. packardi and $L$. cryptus (see Fig. 1a in Korn and Hundsdoerfer, 2006; Mathers et al., 2013b) could have dispersed from Europe westwards to Northern America via the Thulean Bridge (see Fig. S.4), which is thought to have been an important route for faunal exchange in the Early Eocene, at approx. 50-55 Ma (see Sanmartín et al., 2001). Alternatively, the lineage of American endemics could have diverged during a range extension from Europe into Asia during a temporary regression of the Turgai Sea in the Palaeocene (see Sanmartín et al., 2001; the Palaeocene spans 56-66 Ma, see Cohen et al., 2012), followed by an additional eastward dispersal over Beringia to Eastern North America (the single record of a Lepidurus population from South America, that of L. apus patagonicus, might also refer to this lineage, however, presently available data are insufficient to confirm this assumption). The L. apus viridis lineage possibly evolved in Eastern Asia from where it could have reached Australia and New Zealand by long-distance dispersal, facilitated by its non-gonochoric mode of reproduction. Lepidurus couesii likely dispersed over Beringia to North America after the divergence from $L$. arcticus and an initial diversification of the group in Eurasia, as suggested by the wide distribution of morphologically similar forms throughout Eurasia (see Section S.7), including a recently discovered Sardinian lineage that appears to have diverged from a more basal node within this group than $L$. couesii (see Mathers et al., 2013b).

\subsection{Taxonomy}

A trend toward the use of taxonomically incorrect species names can be observed in recent notostracan literature (see e.g. invalid names in Vanschoenwinkel et al., 2012, and in Mathers et al., 2013a; for a detailed discussion, see Section S.8). We therefore urge authors of studies relying entirely on molecular data to pay more attention to the correct application of accepted taxonomic rules (see International Commission on Zoological Nomenclature, 1999).

Our results reinforce the need for further taxonomic revisions in several taxonomic groups, especially in Triops granarius and Lepidurus apus s.l. (see Section 1). Regarding L. apus lubbocki, Mantovani et al. (2009) already concluded that it should be recognised as a separate species, but they refrained from formally reinstating its species status (see Section S.8). Indeed, further investigations including morphology are needed to clarify its taxonomy, especially since we have demonstrated that this subspecies is not even monophyletic.

As pointed out in Section 4.3, a taxonomic revision of the Triassic and Permian fossils that are presently attributed to $T$. cancriformis appears necessary. We therefore elevate $T$. c. minor to full species status as Triops minor Trusheim, 1938 (stat. nov.). We include in this species samples with similar morphology from two additional Upper Triassic fossil beds: 'Triops cancriformis' in Kelber (1999) and 'Triops cf. cancriformis' in Gore (1986). We further elevate $T$. cancriformis permiensis to full species status as Triops permiensis Gand et al., 1997 (stat. nov.). Future studies will need to clarify whether the latter might actually be older than the split between Triops and Lepidurus, which would favour its placement as a separate genus.

\section{Acknowledgments}

We are very thankful to Don Dasis, Eric Gallerne, Alexandre Hassanin, Hervé Huet, Anina Hundsdoerfer, Iwao Iguchi, Giuseppe Ippolito, Pascal Lluch, Dragana Milicic, Brigita Petrov, Didier Pillet and Carmen Rohrbach for providing soils with notostracan eggs, and to Steve Coulson, Don Dasis and Thorid Zierold for providing ethanol-preserved samples for this investigation (in alphabetical order). We are greatly endebted to Anke Müller and Christian Kehlmaier for their dedicated engagement in the sequencing work. Katja Frohberg further contributed to the sequencing work in this study. We are grateful to four anonymous reviewers, as well as Miquel A. Arnedo (Associate Editor) for their suggestions that significantly improved the manuscript. We are very thankful to Felix Sperling for greatly improving the English language of the manuscript.

\section{Appendix A. Supplementary material}

Supplementary data associated with this article can be found, in the online version, at http://dx.doi.org/10.1016/j.ympev.2013.08. 006.

\section{References}

Barnard, K.H., 1929. A revision of the South African Branchiopoda Phyllopoda. Ann. S. Afr. Mus. 29, 181-272.

Bossuyt, F., Brown, R.M., Hillis, D.M., Cannatella, D.C., Milinkovitch, M.C., 2006. Phylogeny and biogeography of a cosmopolitan frog radiation: Late Cretaceous 
diversification resulted in continent-scale endemism in the family Ranidae. Syst. Biol. 55, 579-594.

Briggs, D.E.G., Weedon, M.J., Whyte, M.A., 1993. Arthropoda (Crustacea excluding Ostracoda). In: Benton, M.J. (Ed.), The Fossil Record 2. Chapman \& Hall, London, pp. 321-342.

Bromham, L., Penny, D., 2003. The modern molecular clock. Nat. Rev. Genet. 4, 216 224

Caccone, A., Sbordoni, V., 2001. Molecular biogeography of cave life: a study using mitochondrial DNA from Bathysciine beetles. Evolution 55, 122-130.

Cohen, K.M., Finney, S., Gibbard, P.L., 2012. International Chronostratigraphic Chart, International Commission on Stratigraphy. <http://www.stratigraphy.org/>.

DeSalle, R., Freedman, T., Prager, E.M., Wilson, A.C., 1987. Tempo and mode of sequence evolution in mitochondrial DNA of Hawaiian Drosophila. J. Mol. Evol. 26, 157-164.

Dessimoz, C., Gil, M., 2010. Phylogenetic assessment of alignments reveals neglected tree signal in gaps. Genome Biol. 11, R37.

Dornburg, A., Brandley, M.C., McGowen, M.R., Near, T.J., 2012. Relaxed clocks and inferences of heterogeneous patterns of nucleotide substitution and divergence time estimates across whales and dolphins (Mammalia: Cetacea). Mol. Biol. Evol. 29, 721-736.

Drummond, A.J., Suchard, M.A., 2010. Bayesian random local clocks, or one rate to rule them all. BMC Biol. 8, 114.

Drummond, A.J., Ho, S.Y.W., Phillips, M.J., Rambaut, A., 2006. Relaxed phylogenetics and dating with confidence. PLoS Biol. 4, e88.

Drummond, A.J., Suchard, M.A., Xie, D., Rambaut, A., 2012. Bayesian phylogenetics with BEAUti and the BEAST 1.7. Mol. Biol. Evol.. http://dx.doi.org/10.1093/ molbev/mss075.

Dumont, H.J., Negrea, S.V., 2002. Introduction to the Class Branchiopoda. Backhuys Publishers, Leiden.

Fayers, S.R., Trewin, N.H., 2003. A new crustacean from the Early Devonian Rhynie chert, Aberdeenshire, Scotland. Earth Environ. Sci. Trans. R. Soc. Edinb. 93, 355382.

Ferreira, M.A.R., Suchard, M.A., 2008. Bayesian analysis of elapsed times in continuous-time Markov chains. Can. J. Stat. 36, 355-368.

Folmer, O., Black, M., Hoeh, W., Lutz, R., Vrijenhoek, R., 1994. DNA primers for amplification of mitochondrial cytochrome c oxidase subunit I from diverse metazoan invertebrates. Mol. Mar. Biol. Biotechnol. 3, 294-299.

Gand, G., Garric, J., Lapeyrie, J., 1997. Biocénoses à triopsidés (Crustacea, Branchiopoda) du Permien du bassin de Lodève (France). Geobios 30, 673-700.

Garrouste, R., Clément, G., Nel, P., Engel, M.S., Grandcolas, P., D’Haese, C., Lagebro, L., Denayer, J., Gueriau, P., Lafaite, P., Olive, S., Prestianni, C., Nel, A., 2012. A complete insect from the Late Devonian period. Nature 488, 82-85.

GeneStudio Inc., 2011. SeqVerter (TM), Sequence Conversion Utility. GeneStudio, Inc. <http://genestudio.com/>

Gernhard, T., 2008. The conditioned reconstructed process. J. Theor. Biol. 253, 769778 .

Gore, P.J.W., 1986. Triassic Notostracans in the Newark Supergroup, Culpeper Basin, Northern Virginia. J. Paleontol. 60, 1086-1096.

Guindon, S., Gascuel, O., 2003. A simple, fast and accurate method to estimate large phylogenies by maximum-likelihood. Syst. Biol. 52, 696-704.

Hall, T.A., 1999. BioEdit: a user-friendly biological sequence alignment editor and analysis program for Windows 95/98/NT. Nucleic Acids Symp. Ser. 41, 95-98.

Hegna, T.A., 2011. Fossil insights on notostracan limb differentiation \& evolution. Ecdysiast 30, 9.

Hegna, T.A., Ren, D., 2010. Two new "Notostracans”, Chenops gen. nov. and Jeholops gen. nov. (Crustacea: Branchiopoda:? Notostraca) from the Yixian Formation, Northeastern China. Acta Geol. Sin. 84, 886-894.

Hessen, D.O., Rueness, E.K., Stabell, M., 2004. Circumpolar analysis of morphological and genetic diversity in the Notostracan Lepidurus arcticus. Hydrobiologia 519, 73-84.

Ho, S.Y.W., Lanfear, R., Bromham, L., Phillips, M.J., Soubrier, J., Rodrigo, A.G., Cooper, A., 2011. Time-dependent rates of molecular evolution. Mol. Ecol. 20, $3087-$ 3101.

International Commission on Zoological Nomenclature, 1999. International Code of Zoological Nomenclature, fourth ed. The International Trust for Zoological Nomenclature, London.

Kelber, K.-P., 1999. Triops cancriformis (Crustacea, Notostraca): Ein bemerkenswertes Fossil aus der Trias Mitteleuropas. In: Hauschke, N., Wilde, V. (Eds.), Trias - Eine ganz andere Welt. Verlag Dr. Friedrich Pfeil, Munich, pp. 383-394.

King, J.L., Hanner, R., 1998. Cryptic species in a "Living Fossil" lineage: taxonomic and phylogenetic relationships within the genus Lepidurus (Crustacea: Notostraca) in North America. Mol. Phylogenet. Evol. 10, 23-36.

Knowlton, N., Weigt, L.A., 1998. New dates and new rates for divergence across the Isthmus of Panama. Proc. R. Soc. Lond. B Biol. Sci. 265, 2257-2263.

Korn, M., Hundsdoerfer, A.K., 2006. Evidence for cryptic species in the tadpole shrimp Triops granarius (Lucas, 1864) (Crustacea: Notostraca). Zootaxa 1257, 57-68.

Korn, M., Marrone, F., Pérez-Bote, J.L., Machado, M., Cristo, M., Cancela da Fonseca, L., Hundsdoerfer, A.K., 2006. Sister species within the Triops cancriformis lineage (Crustacea, Notostraca). Zool. Scr. 35, 301-322.

Korn, M., Green, A.J., Machado, M., García-de-Lomas, J., Cristo, M., Cancela da Fonseca, L., Frisch, D., Pérez-Bote, J.L., Hundsdoerfer, A.K., 2010. Phylogeny, molecular ecology and taxonomy of southern Iberian lineages of Triops mauritanicus (Crustacea: Notostraca). Org. Divers. Evol. 10, 409-440.
Longhurst, A.R., 1955. A review of the Notostraca. Bull. Br. Mus. Nat. Hist. Zool. 3, 1 57.

Löytynoja, A., Goldman, N., 2008. Phylogeny-aware gap placement prevents errors in sequence alignment and evolutionary analysis. Science 320, 1632-1635.

Löytynoja, A., Goldman, N., 2010. WebPRANK: a phylogeny-aware multiple sequence aligner with interactive alignment browser. BMC Bioinform. 11, 579.

Lynch, J.E., 1966. Lepidurus lemmoni Holmes: a redescription with notes on variation and distribution. Trans. Am. Microsc. Soc. 85, 181-192.

Lynch, J.E., 1972. Lepidurus couesii Packard (Notostraca) redescribed with a discussion of specific characters in the genus. Crustaceana 23, 43-49.

Lynch, M., Jarrell, P.E., 1993. A method for calibrating molecular clocks and its application to animal mitochondrial DNA. Genetics 135, 1197-1208.

Mantovani, B., Cesari, M., Scanabissi, F., 2004. Molecular taxonomy and phylogeny of the 'living fossil' lineages Triops and Lepidurus (Branchiopoda: Notostraca) Zool. Scr. 33, 367-374.

Mantovani, B., Cesari, M., Scanabissi, F., 2009. Molecular taxonomy and phylogeny of Italian Lepidurus taxa (Branchiopoda: Notostraca). Ital. J. Zool. 76, 358-365.

Marko, P.B., 2002. Fossil calibration of molecular clocks and the divergence times of geminate species pairs separated by the Isthmus of Panama. Mol. Biol. Evol. 19, 2005-2021.

Mathers, T.C., Hammond, R.L., Jenner, R.A., Hänfling, B., Gómez, A., 2013a. Multiple global radiations in tadpole shrimps challenge the concept of 'living fossils' PeerJ 1, e62.

Mathers, T.C., Hammond, R.L., Jenner, R.A., Zierold, T., Hänfling, B., Gómez, A., 2013b. High lability of sexual system over 250 million years of evolution in morphologically conservative tadpole shrimps. BMC Evol. Biol. 13, 30.

Müller, K., 2005. SeqState - primer design and sequence statistics for phylogenetic DNA data sets. Appl. Bioinform. 4, 65-69.

Nylander, J.A., Wilgenbusch, J.C., Warren, D.L., Swofford, D.L., 2008. AWTY (are we there yet?): a system for graphical exploration of MCMC convergence in Bayesian phylogenetics. Bioinformatics 24, 581-583.

Olesen, J., 2009. Phylogeny of Branchiopoda (Crustacea) - character evolution and contribution of uniquely preserved fossils. Arthropod Syst. Phylogeny 67, 3-39.

Penny, D., Hendy, M.D., 1985. The use of tree comparison metrics. Syst. Zool. 34, 75 82

Posada, D., 2008. JModelTest: phylogenetic model averaging. Mol. Biol. Evol. 25, $1253-1256$.

Prasad, V., Farooqui, A., Tripathi, S.K.M., Garg, R., Thakur, B., 2009. Evidence of late Palaeocene-early Eocene equatorial rain forest refugia in southern Western Ghats, India. J. Biosci. 34, 777-797.

Rambaut, A., Drummond, A.J., 2009. Tracer v1.5. <http://tree.bio.ed.ac.uk/software/ tracer/>.

Richter, S., Olesen, J., Wheeler, W.C., 2007. Phylogeny of Branchiopoda (Crustacea) based on a combined analysis of morphological data and six molecular loci. Cladistics 23, 301-336.

Rogers, D.C., 2001. Revision of the Nearctic Lepidurus (Notostraca). J. Crustacean Biol. 21, 991-1006.

Romano, S.L., Palumbi, S.R., 1997. Molecular evolution of a portion of the mitochondrial $16 \mathrm{~S}$ ribosomal gene region in scleractinian corals. J. Mol. Evol. 45, 397-411.

Ronquist, F., Teslenko, M., van der Mark, P., Ayres, D.L., Darling, A., Höhna, S., Larget B., Liu, L., Suchard, M.A., Huelsenbeck, J.P., 2012. MrBayes 3.2: efficient Bayesian phylogenetic inference and model choice across a large model space. Syst. Biol. http://dx.doi.org/10.1093/sysbio/sys029.

Sanmartín, I., Ronquist, F., 2004. Southern Hemisphere biogeography inferred by event-based models: plant versus animal patterns. Syst. Biol. 53, 216-243.

Sanmartín, I., Enghoff, H., Ronquist, F., 2001. Patterns of animal dispersal, vicariance and diversification in the Holarctic. Biol. J. Linn. Soc. Lond. 73, 345-390.

Sassaman, C., Simovich, M.A., Fugate, M., 1997. Reproductive isolation and genetic differentiation in North American species of Triops (Crustacea: Branchiopoda: Notostraca). Hydrobiologia 359, 125-147.

Scotese, C.R., 2012. PALEOMAP Project. <http://www.scotese.com/> (accessed 01.09.12).

Silvestro, D., Michalak, I., 2011. RaxmlGUI: a graphical front-end for RAxML. Org. Divers. Evol.. http://dx.doi.org/10.1007/s13127-011-0056-0.

Simmons, M.P., Ochoterena, H., 2000. Gaps as characters in sequence-based phylogenetic analyses. Syst. Biol. 49, 369-381.

Simon, C., Nigro, L., Sullivan, J., Holsinger, K., Martin, A., Grapputo, A., Franke, A., McIntosh, C., 1996. Large differences in substitutional pattern and evolutionary rate of 12S ribosomal RNA genes. Mol. Biol. Evol. 13, 923-932.

Stamatakis, A., 2006. RAxML-VI-HPC: maximum likelihood-based phylogenetic analyses with thousands of taxa and mixed models. Bioinformatics 22, 26882690.

Stillman, J.H., Reeb, C.A., 2001. Molecular phylogeny of Eastern Pacific Porcelain crabs, genera Petrolisthes and Pachycheles, based on the mtDNA 16S rDNA sequence: phylogeographic and systematic implications. Mol. Phylogenet. Evol. $19,236-245$.

Straka, U., 2004. Aktuelle Vorkommen von Groß-Branchiopoden (Crustacea: Anostraca, Notostraca, Conchostraca) im Tullner Feld (Niederöstereich). Ann. Naturhist. Mus. Wien 105 B, 35-45.

Swofford, D.L., 2003. PAUP* - Phylogenetic Analysis Using Parsimony ( ${ }^{*}$ and othe methods). Version 4. Sinauer Associates, Sunderland, MA.

Tamura, K., Dudley, J., Nei, M., Kumar, S., 2007. MEGA4: molecular evolutionary genetics analysis (MEGA) software version 4.0. Mol. Biol. Evol. 24 1596-1599. 
Tasch, P., 1969. Branchiopoda. In: Moore, R.C. (Ed.), Treatise on Invertebrate Paleontology, Part R, Arthropoda 4. The Geological Society of America and the University of Kansas, Boulder, Colorado, pp. R128-R191.

Tasch, P., 1987. Fossil Conchostraca of the Southern Hemisphere and continental drift, Memoir 165. The Geological Society of America, Boulder, Colorado.

Tchernyshev, B.I., 1940. Mesozoic Branchiopoda from Turkestan and the Transbaikal. J. Geol. Acad. Sci. Ukr. SSR 7, 5-46.

Trusheim, F., 1938. Triopsiden (Crust. Phyll.) aus dem Keuper Frankens. Palaeontol. Z. $19,198-216$

Vanschoenwinkel, B., Pinceel, T., Vanhove, M.P.M., Denis, C., Jocque, M., Timms, B.V. Brendonck, L., 2012. Toward a global phylogeny of the "living fossil" crustacean order of the Notostraca. PLoS ONE 7, e34998.
Vekhov, N.V., 1992. Lepidurus mongolicus sp. nov., a new species of tadpole shrimp (Crustacea Notostraca Triopsidae) from semideserts of Central Asia (Mongolia). Arthropoda Sel. 1, 89-93.

Yang, Z., 1994. Maximum Likelihood phylogenetic estimation from DNA sequences with variable rates over sites: approximate methods. J. Mol. Evol. 39, 306-314.

Yang, T.-y., Hong, Y.C, 1980. Discovery of fresh-water Triopsids from the Upper Jurassic Dabeigou formation of Weichang, Hebei, China and its bearing on the classification of the family Triopsidae Martalent. Acta Palaeontol. Sin. 19, 91-99. 